\title{
Proppant Backflow: Mechanical and Flow Considerations
}

\author{
J. McLennan ${ }^{1,2, \$}$, I. Walton ${ }^{2}$, J. Moore ${ }^{2}$, D. Brinton ${ }^{3}$, and J. Lund ${ }^{4}$ \\ ${ }^{1}$ Department of Chemical Engineering, University of Utah \\ ${ }^{2}$ Energy \& Geoscience Institute at the University of Utah \\ ${ }^{3}$ Urban Science \\ ${ }^{4}$ MegaDiamond, A Schlumberger Company, formerly TerraTek, Inc., A Schlumberger \\ Company
}

\begin{abstract}
One of the concerns of using proppant in geothermal wells, and particularly in enhanced geothermal systems, is proppant flowback. Particulate proppant maintain post-closure conductivity in hydraulically opened fractures. If that proppant is displaced from the nearwellbore region, either due to overflushing during stimulation or flowback to the wellbore at any time, the reduced fracture width chokes the injection or production. Two intermediate-scale laboratory analogs of a propped hydraulic fracture were prepared, and fluid was flowed through a normally stressed, propped fracture into a central wellbore. The tests were conducted in a polyaxial load frame. Acoustic/microseismic activity was measured during the injection programs. In one scenario - radial flow through a transverse fracture to a wellbore - the results suggest the creation of flow channels and nominally intact propped zones around the channels, maintaining fracture aperture. In the other-linear flow through a longitudinal fracture into a wellbore - there was substantially more proppant removal. The measurements have shown a greater tendency for proppant flowback in a linear flow situation (proppant movement is kinematically more restricted for radial convergent flow). The pressure gradients causing flow are exceedingly small and restraining flowback will be difficult. Convergent flow relationships could be an issue for injector wells, which will experience fluid flowback during hard shutdowns. [SLD: Shutdown as one word when used as a noun is an SPE convention; the SPE style guide (http://www.spe.org/authors/docs/styleguide.pdf) was used for industry terms. For general style, the journal guidelines were used (http://www.elsevier.com/journals/geothermics/0375-6505/guide-for-authors).]
\end{abstract}

Keywords: proppant, flowback, radial convergent flow, linear flow, Reynolds' number

\section{Background on Proppant Flowback}

Proppant flowback and choking are well known in the petroleum industry and are speculated to be potentially troublesome by the geothermal industry, at least for production wells. Arguments that flowback will not be a problem in injection wells are misplaced, for at least two reasons. Displacing proppant laterally away from the well can leave a poorly propped zone or channels immediately around a well. This overflushing can occur due to unintentional hydraulic fracturing or dynamic pressure redistribution when an injector is shut in and also during workover operations. Similarly, back-producing proppant into a wellbore can happen as a consequence of any intentional or unintentional flowback, which may occur after hydraulic fracturing, during pressure redistribution when wells are shut in [for example, a water hammer during a hard shutdown can send a pressure pulse into and subsequently out of a fracture (Santarelli et al., 2011)], and during production).

$\$$ Corresponding Author: jmclennan@egi.utah.edu, University of Utah, Department of Chemical Engineering, 50 South Central Campus Drive, Salt Lake City, UT 84112, 1-801-587-7925. 
The petroleum literature has many examples of the consequences of proppant back-production, ranging from erosion to choke skins. Raymond and Binder (1967) and Sinclair et al. (1983) were early advocates of maintaining near-wellbore conductivity. Very small reductions in packed fracture width near the wellbore can effectively negate any stimulation carried out. Romero et al. (2003) provided a review and analytical relationships that accounted for choke skins due to nearwellbore removal of proppant. Robinson et al. (1988) described production impairment due to proppant damage by crushing, conductivity reduction, and flowback.

Milton-Tayler et al. (1992) carried out numerical and experimental work that was quite insightful. The parameters that they assessed and their observations are as follows:

- Fracture aperture: “... there existed a narrow band of apertures over which a pack went from stable to unstable."

- Closure stress: The degree of embedment affected stability. In high-modulus, strong rock, embedment may be relatively small and flowback may not be substantially restricted by embedment alone. Roughness may be more of an issue, but it was not considered explicitly.

- Hardness: Hardness is the force applied to a contact (for example, a proppant particle) divided by the cross-sectional area of the indentation into an adjoining medium. It is intuitive that increased hardness will correlate with reduced indentation and less frictional or kinematic resistance to proppant moving due to fluid drag.

- Differential pressure or drawdown: It was not apparent that the pressure gradient could be readily isolated as a controlling factor. This was because of frictional interaction between proppant and the fracture walls. If, however, the width, embedment, and closure stress conditions produce a metastable pack, increasing drawdown can trigger sand production.

- Proppant type: Rougher, more angular proppant was seen to be more stable; proportional to the angle of internal friction of the proppant. The stability is affected by the proppant size and fracture aperture.

- Channels: Experiments demonstrated that packs with physical channels were less stable than those without channels. [SLD: The other bullets do not have explicit citations to Milton-Tayler et al. and the introductory sentence serves as the citation.]

Andrews and Kjørholt (1998) cited rules-of-thumb that fracture widths wider than five proppant diameters were inherently unstable. Computational work by others had supported that hypothesis (Asgian et al., 1995). Goel and Shah (1999) showed a dependence of proppant pack stability on closure stress. In some cases, the relationship is counterintuitive, with proppant flowback occurring at a lower critical flow rate when closure stress was increased. Goel and Shah (1999) also demonstrated the influence of drag forces, as did Andrews and Kjørholt (1998), who described closure stress and interparticle friction as mechanisms to promote development of irregularly shaped metastable arches that resist proppant movement to the fracture mouth. This suggested that buckled columns of proppant in front of the arch were not bearing the closure stress. With sufficient drag from the moving fluid, the integrity of the arch can be compromised and additional proppant production can occur. Hydraulic destabilization, shear failure, and crushing were designated as complimentary mechanisms of proppant pack deterioration that could all accelerate flowback. Three key parameters stand out for proppant hydraulic mobility- 
diameter (first-order relevance), closure stress (second-order diametral dependence), and drag (third-order diametral dependence).

Andrews and Kjørholt (1998) also reported that "... the viscosity of the fluid flowing back is, in itself, not critical to flowback since the fluid destabilizing force is a body force and not a viscous drag force. Calculations show that the drag force is typically an order of magnitude smaller than the body force." However, they acknowledged two-phase as being potentially important because of high local gradients across a proppant grain temporarily swept by one flowing phase and because of loss of capillary tension.

Daneshy (2005) provided some mechanistic insight, describing the potential for saltation-like movement across the top of partially propped vertical fractures. He emphasized the importance of the initial geometry of the placed proppant.

Parker et al. (1999) [SLD: Please see my note in the reference list.] provided numerical and experimental data. They described resistive and driving mechanisms: angle of repose (this is frictional resistance), interactive forces (capillarity), hydrodynamic forces, and mechanical forces (closure stress and interparticle contact stress). The experimental work used flow through a parallel plate analog, a perforation analog, and an API linear flow cell. The numerical work used probabilistic methods to demonstrate the evolution of the interface between a propped area and an open channel [see also King (1988)].

One of the least understood elements is the influence of fracture roughness on conductivity and on impending pack instability. One of the few references in the petroleum literature addressing this is Fredd et al. (2001). These authors considered the relationship between conductivity and asperities on sheared surfaces.

Finally, one of the more frequently cited references for numerical evaluations is Asgian et al. (1995). A distinct element method (DEM) simulator was used to evaluate movement of spherical proppant surrogates being acted upon by flowing fluid in a closed fracture. The influence of the flowing fluid was represented by explicitly including pressure and shear components of the drag acting on the individual particles. The relationships are shown below.

The pressure component contributing to drag (on each particle) is

$$
F_{p}=\frac{4}{3} \pi r^{3} \frac{d p}{d x}
$$

where $F_{p}$ is the pressure drag $(\mathrm{N}), r$ is the particle radius $(\mathrm{m}), p$ is pressure $(\mathrm{Pa})$, and $x$ is the distance along the fracture in the direction of the flow $(\mathrm{m})$.

The shear component contributing to drag (on an isolated spherical particle, for laminar flow) is

$$
F_{s}=6 \pi V_{s} \mu r \rightarrow F_{s}=6 \pi\left(\frac{k}{\mu} \frac{d p}{d x} \frac{1}{\phi}\right) \mu r=6 \pi \frac{k}{\phi} \frac{d p}{d x} r
$$


where $F_{s}$ is the drag attributed to viscous effects $(\mathrm{N}), V_{s}$ is the superficial flow velocity $(\mathrm{m} / \mathrm{s}), \mu$ is the dynamic viscosity $(\mathrm{Pa} \cdot \mathrm{s}), k$ is the permeability $\left(\mathrm{m}^{2}\right)$, and $\phi$ is the porosity (dimensionless).

These two equations demonstrate the predominant importance of pressure-related drag [Eq. (1)] - the dimensions of the proppant and the pressure gradient are the dominant factors.

\section{Challenge}

The results of proppant applications in oilfield and geothermal development clearly demonstrate the necessity of achieving and maintaining near-wellbore conductivity. Most conductivity measurements are made in relatively small-scale, linear flow tests, and proppant movement is largely prevented by applying low pressure gradients and mechanically immobilizing proppant movement out of the testing fixtures. Thus, it was desirable to perform similar tests on a larger scale in a polyaxial loading frame and simulate conductive fractures that could potentially produce proppant into a wellbore. Although the scale is not substantially different from the dimensions of standard API proppant conductivity flow cells, the loading system that was used allowed simulation of conditions that might be analogous to backflow (either intentionally or because of wellbore dynamics). Of particular interest was developing a better understanding of the potential for near-wellbore flowback and the threshold conditions for proppant movement under certain in-situ conditions. Once these threshold values can be established under a particular set of experimental conditions, it may be possible to extrapolate observations using numerical methods.

\section{Experimental Approach}

Conventional propped fracture conductivity measurements are well known to the petroleum industry; see, for example, Gidley et al. (1989). From a geothermal industry perspective, Mauer Engineering (1980) and Duenckel et al. (2011) have carried out laboratory measurements at temperature to assess conductivity in propped, mechanically immobilized geothermal situations. Elevated temperature measurements were also reported by Stoddard et al. (2011). Those measurements were performed on 30/60 bauxite proppant subjected to $13.79 \mathrm{MPa}$ normal stress at temperatures up to $200^{\circ} \mathrm{C}$. In standard, linear fracture flow experiments such as these (linear implies parallel flow lines), flowing fluid pressure gradients along the fracture are small, and proppant movement is inhibited by screens at the downstream end of the proppant pack. As noted above, a major concern of using proppant in geothermal applications is that backproduction into the well can occur if the proppant is not adequately immobilized. If this is the case, the questions that arise are: 1) Is the predicted conductivity still representative deep into the fracture or is the proppant back-production progressively moving deeper into the fracture? and 2) Does the back-production reduce conductivity or is it just a local phenomenon where adjacent propped regions continue to have load-bearing capacity and hold the fracture open? This last possibility could even increase conductivity_long-term integrity will be a critical issue.

In the present work, two large-scale block experiments were conducted. In each, a 1-inch diameter hole, representing the wellbore, was drilled into a granite block (Fig. 1), which was then mechanically split to yield a rough surface that might be analogous to an actual fracture surface. Although Fredd et al. (2001) and van Dam and de Pater (1999) offered some insight into the role of roughness, it is still uncertain whether or not the roughness of the fractured block accurately represents the roughness of a fracture in-situ. The fracture plane was packed with 
30/60 bauxite at a prescribed concentration, stress was applied normal to the fracture, and flow was initiated from the external block boundaries. The first block test simulated convergent flow towards a wellbore or perforation. A follow-on test simulated linear flow towards a wellbore, as might occur in an openhole environment with a propped, longitudinal fracture. Acoustic/microseismic activity, pressures and flow rates were monitored and the mass of produced bauxite proppant was measured continuously. Computerized tomographic (CT) imaging was carried out after the testing was completed.

\section{Procedures}

A block of Barre Granite, a fine-grained, equigranular granite, was saw cut flat and parallel with nominal dimensions of $0.203 \mathrm{~m} \times 0.203 \mathrm{~m} \times 0.357 \mathrm{~m}$. Bulk density is on the order of $2.68 \mathrm{~g} / \mathrm{cm}^{3}$. Unconfined compressive strength is reported to vary between 117 and $172 \mathrm{MPa}$, and Young's modulus is approximately $55 \mathrm{GPa}$.

\subsection{Convergent Radial Flow Test}

A 25.4-mm diameter vertical hole was drilled parallel to the long axis of the block (Fig. 1). The hole was through-going so that effluent with proppant could be collected and measured through the bottom of the block. Biscuits (disk-shaped recesses) and slots for cables (see Fig. 1C) were prepared on the outside of the block so that acoustic transducers could be installed to monitor microseismic activity during flowback. The periphery of the block was scored with a rock saw at mid-height normal to the long axis of the block. This provided a guide for the fracture that was created by wedge splitting the block. The bottom half of the block was placed in a flexible canister, and the surface was covered with $30 / 60$ bauxite at a concentration of $0.105 \mathrm{~kg} / \mathrm{m}^{2}$. The annular space between the block and the canister was also filled with 30/60 bauxite. This allowed external flow from all sides of the block through the bauxite-filled fracture. Although difficult to resolve, Fig. 2A shows the fracture surface covered with bauxite and a tube in the wellbore to prevent proppant movement during assembly. The tube was removed prior to testing. This borehole vents downwards to an external gravimetric collection system, which determines the buoyant weight of the recovered proppant.

With the bottom half of the block in place, a casing stub was cemented part way into the hole in the upper block, staying well away from the fracture. This was sealed prior to testing. The acoustic transducers and cables were grouted in (Figs. 2B and 2C), and the upper block was positioned on top of its lower mate with the fractured faces separated by the bauxite proppant pack. The annular space between the upper block and the canister was also filled with bauxite proppant, and tubing was inserted in this external proppant pack to allow the fluid to flow through the horizontally oriented fracture to the wellbore from the block boundaries. Fig. 3A is an elevation view of the entire setup before installation in the polyaxial vessel. After all components were installed in the canister, this package was lowered into the polyaxial testing frame (Fig. 3C).

Fig. 1. A) View of the granite block with nominal external dimensions of $0.203 \mathrm{~m} \times 0.203 \mathrm{~m} \times 0.357 \mathrm{~m}$. The edges were scored and a fracture was mechanically created by splitting with a wedge. B) The two block halves stacked with no proppant. The 25.4-mm diameter central hole is visible in this view and in Fig. 1A. C) Biscuits were cut on the ends of the block for the installation of microseismic transducers. 
Fig. 2. Fabrication of the radially convergent flow sample. A) View looking down on the proppant-covered lower block half. A coiled sheet forming a tube extending vertically out of the lower block half is designed to keep proppant in place during fabrication and is extracted after the top block is lowered in place. B) Top half of the fractured block, showing microseismic biscuits and cable conduits cut into the rock. C) Microseismic/acoustic transducers have been installed. D) Microseismic/acoustic transducer cabling is seen and the block has been dropped into the flexible external container. (E) View of external canister containing the sample.

Fig. 3. A) Radial convergent flow: Elevation view of block, with the wellbore venting downwards to a gravimetric measurement system (not shown). The dimensions on the plans are in inches. The approximate proppant pack thickness is indicated as $6 \mathrm{~mm}(0.25$ inches). The entire unit was lowered into a reaction frame allowing independent application of stresses in three orthogonal directions. This configuration allows radial convergent flow into the wellbore. Key: 1 - bauxite bead layer, 2 - bottom loading plate, 3 - spacer, 4 - casing stub, 5 - granite sample, 6 lower ram, 7 - lower urethane seal, 8 - sealing canister, 9 - upper loading plate, 10 - upper ram, 11 - upper urethane seal. B) Linear flow configuration. Key: 1 - bauxite bead layer, 2 - bottom loading plate, 3 - spacer, 4 granite sample, 5 - spacer, 6 - lower ram, 7 - lower urethane seal, 8 - sealing canister, 9 - upper loading plate, 10 upper ram, 11 - upper urethane seal, 12 - urethane borehole plug, 13 - urethane seal, 14 - upper urethane seal. C) Polyaxial frame with sample installed.

\subsection{Linear Flow Test}

The configuration described above allowed radial convergent flow through a fracture into a wellbore normal to the fracture. A second block was prepared for linear flow. Biscuits (diskshaped recesses) and slots for cables (see Fig. 4A) were prepared on the outside of the block so that acoustic transducers could be installed to monitor microseismic activity during flowback. The periphery of the block was scored with a rock saw at mid-height normal to the long axis of the block. This provided a guide for the fracture that was created by wedge splitting the block. A drainhole (12.7-mm diameter) was drilled normal to the fracture through one block face (Fig. 4B). This would be oriented to allow produced proppant to drain out of the wellbore that would subsequently be drilled parallel to the fracture surface, simulating a longitudinal fracture. The blocks were immobilized with spacers inserted in the fracture, and a 25.4-mm diameter wellbore was drilled along the fractured surface (Fig. 4C). This intersected the drainhole (Fig. 4D). The ends of the fracture and the wellbore were sealed with polyurethane. The bottom half of the block was placed in a flexible canister, and the surface was covered with 30/60 bauxite at a concentration of $0.105 \mathrm{~kg} / \mathrm{m}^{2}$ (Fig. 4E). The annular space between the block and the canister was also filled with 30/60 bauxite. This allowed external flow from two sides of the block through the bauxite-filled fracture. The drainhole vents downwards to an external gravimetric collection system, which determines the buoyant weight of the recovered proppant. Fig. 3B is an engineering drawing showing the setup. After all components were installed in the canister, this package was lowered into the polyaxial testing frame (Fig. 3C).

Fig. 4. A) View of the split granite block (for the linear flow test) with nominal external dimensions of $0.203 \mathrm{~m} \times$ $0.203 \mathrm{~m} \times 0.357 \mathrm{~m}$. The edges were scored and a fracture was mechanically created by splitting with a wedge. B) A drainhole was drilled to allow produced proppant to exit the block and be gravimetrically collected. C) Biscuits were cut on the ends of the block for the installation of acoustic transducers. A wellbore was drilled along the fracture plane, intersecting the drainhole. D) View of wellbore, drainhole, and granite fracture surface. E) View of wellbore, drainhole, bauxite on the lower half of the block, and sealed ends. After mating of the lower and the upper blocks, external flow will be directed through the proppant pack linearly towards the wellbore.

\section{Testing Chronology}

\subsection{Radially Convergent Flow}


The entire testing chronology is shown in Fig. 5. A stress of $13.79 \mathrm{MPa}$ was isotropically applied to each block face using hydraulic flatjacks. The horizontal stresses (parallel to the propped fracture) were increased to 17.24 MPa. All stresses were then held constant. Injection was started and was gradually increased until the dead volume in the injection lines and the bauxite proppant pack (around the circumference of the block) were filled. The proppant pack surrounding the block below the level of the horizontal fracture had to be saturated before flow would occur from the block exterior, through the propped fracture, into the central wellbore, and out of the system through the bottom of the apparatus. The first fluid produced through the wellbore and fixtures occurred at 110 minutes (Fig. 5). Rates were progressively increased until there was evidence of proppant production.

The first evidence of proppant being produced from the fracture was at 195 minutes when the external flow rate was $280 \mathrm{ml} / \mathrm{min}$. The differential fluid pressure (Fig. 5) when proppant first appeared was $\sim 10 \mathrm{kPa}$ gauge. At approximately 226 minutes from the start of the test, the external injection rate was increased to $520 \mathrm{ml} / \mathrm{min}$, and the rate of proppant production subsequently started to noticeably increase. The external fluid pressure was $39 \mathrm{kPa}$ gauge. [SLD: Using the abbreviation min for minutes and s for seconds - in combined units only - follows the SPE guidelines for SI units; the American Chemical Society guidelines also use s for second in combined units.]

At 230 minutes, the normal (closure) stress on the proppant pack was increased to $\sim 17 \mathrm{MPa}$. The rate of proppant production stabilized. When the normal stress was further increased to 20.5 $\mathrm{MPa}$, the rate of proppant production increased dramatically. Further increases in normal stress could not stabilize the proppant production. In fact, increased normal stress applied at approximately 238 and 244 minutes both correspond to increases in proppant production rate, even though the fluid flow rate was held constant. This is consistent with observations of Goel and Shah (1999).

Fig. 5. Overall testing chronology for the radial convergent flow test. The differential pressure is the pressure drop through the hydraulic fracture. The normal stress is the closure stress analog - stress acting normal to the propped fracture. The produced bauxite weight reflects proppant production out of the fracture into the wellbore. Proppant was produced at slightly above background levels (i.e., periodic and small masses) until the injection rate change at approximately 226 minutes. After the normal stress was increased to approximately $20.5 \mathrm{MPa}$ (at approximately 239 minutes), proppant production increased substantially. A further increase in normal stress (at 244 minutes) corresponded with a further increase in proppant production rate. Proppant production was arrested only when the flow was terminated.

\subsection{Linear Flow}

The entire testing chronology is shown in Fig. 6. The protocols were similar to the first test. Proppant production was impeded because of the configuration of plumbing leaving the vessel. The produced proppant weight has been normalized to exclude some earlier solids productionit should be treated as a relative rather than absolute indicator.

Fig. 6. Overall testing chronology for the linear flow test. The differential pressure is the pressure drop through the hydraulic fracture. The normal stress is the closure stress analog-stress acting normal to the propped fracture. The produced bauxite weight reflects proppant production out of the fracture into the wellbore.

\section{Results}




\subsection{Radially Convergent Flow}

Fluid was first produced at about 110 minutes. Over the next 85 minutes, the flow rate was progressively increased in small steps with no apparent production of proppant from the pack. Over this period, it can be expected that the pressure drop across the pack may be adequately predicted by Darcy's law (formulated for a radial flow geometry).

Fig. 7 shows the variation of injection pressure with flow rate for flow rates less than $130 \mathrm{ml} / \mathrm{min}$ $\left(2.2 \mathrm{~cm}^{3} / \mathrm{s}\right)$. The injection pressure has been initialized to zero at zero flow rate to account for the hydrostatic head between the injection point and the location of the pressure gauge. A straight line through the origin has been fitted to the data for flow rates between 1 and $2 \mathrm{~cm}^{3} / \mathrm{s}$, in accordance with Darcy's law. At flow rates less than $1 \mathrm{~cm}^{3} / \mathrm{s}$, the injection pressure is higher than predicted by the Darcy fit. This behavior suggests the proppant pack had not yet been fully saturated with fluid.

Fig. 8 shows the variation of (initialized) injection pressure as a function of the injection rate for the period when the stress normal to the fracture was maintained constant. The straight line marked "Darcy fit" has the same slope as in Fig. 7 and represents a reasonable fit to the data at low flow rates, but clearly not at the higher rates.

Fig. 7. The injection pressure is the upstream pressure minus zero (atmospheric gauge pressure existing at the exit from the fracture). The raw upstream pressure reading was corrected to try to reflect the pressure drop occurring only through the horizontal fracture. Upstream pressure was plotted against rate (before fluid breakthrough). A basic first-order fit was used, and this was extrapolated to correct differential pressures after fluid breakthrough.
Fig. 8. The injection pressure is the upstream pressure minus zero (atmospheric gauge pressure existing at the exit from the fracture). This figure shows the fit using Darcy flow relationships (see also Fig. 7) and deviations from this fit at higher flow rates. The closure stress for all of these data was maintained constant at 13.79 MPa.

The apparent fracture conductivity was estimated as follows:

$$
k_{f} w=\zeta \frac{Q \mu B}{p_{e}-p_{w f}} \ln \left(\frac{r_{e}}{r_{w}}\right)
$$

This is a steady-state manipulation for radial flow where $k_{f}$ is the fracture permeability $\left(\mathrm{m}^{2}\right), w$ is the average fracture width (m), $k_{f} w$ is the fracture conductivity (md-ft), $Q$ is the volumetric flow rate $\left(\mathrm{m}^{3} / \mathrm{s}\right), \mu$ is the dynamic viscosity $(\mathrm{Pa} \cdot \mathrm{s}), B$ is the formation volume factor (1.0 in this case), $p_{e}$ is the external pressure $(\mathrm{Pa}), p_{w f}$ is the wellbore pressure-atmospheric $(\mathrm{Pa}), r_{w}$ is the wellbore radius $(\mathrm{m}), r_{e}$ is the external radius derived from an equivalent circular area for the block $(\mathrm{m})$, and $\zeta$ is a units conversion factor yielding fracture conductivity in units of md-ft.

Using the test parameters described above, the measured slope in Figs. 7 and 8 corresponds to a fracture conductivity of $870 \mathrm{md}-\mathrm{ft}$, but it was not constant. Fig. 9 shows values of the fracture conductivity for the first 115 minutes of the test (from 110 minutes to 225 minutes) during which time the normal stress on the fracture was maintained constant. The Darcy behavior shown in 
Fig. 7 lasted to approximately 175 minutes (refer to Fig. 5). Fig. 10 shows a larger snapshot of conductivities, including time after approximately 230 minutes when the stress normal to the proppant pack was increased.

Fig. 9. Relationship between fracture conductivity, injection pressure and injection rate during radially convergent flow. The stress normal to the propped fracture was maintained constant during this portion of the test.

Fig. 10. Relationship between decreasing fracture conductivity, time, and proppant production during radially convergent flow. This plot shows time beyond that indicated in Fig. 9. The rate of proppant production accelerates just before 230 minutes. The injection rate change at approximately 226 minutes may have triggered this increase in proppant production. Increases in the closure stress appeared to destabilize the proppant further.

The measured conductivities suggest that the testing data may be interpreted in terms of distinct phases that are described below. Mechanisms are hypothesized. They may not be unique and alternative explanations are quite possible. The observations suggest the evolution of the proppant pack can be divided into five sequential phases with increasing time, summarized below.

Phase 1: Pack Saturation. From 110 to approximately 130 minutes, the injection rate was increased to $1 \mathrm{~cm}^{3} / \mathrm{s}$. Fig. 9 shows that the fracture conductivity increases with flow rate during this phase. These observations are consistent with the hypothesis that during this phase the proppant pack has not yet been fully saturated with injection fluid and that initially there was an additional resistance to flow related to the presence of both air and injection fluid in the pack. This is an experimental artifact and not generally relevant in field situations.

Phase 2: Darcy Flow. From 130 until $\sim 65$ minutes, the fracture conductivity remained constant at about $870 \mathrm{md}-\mathrm{ft}$ as the injection rate was increased from $60 \mathrm{ml} / \mathrm{min}\left(1.0 \mathrm{~cm}^{3} / \mathrm{s}\right)$ to $170 \mathrm{ml} / \mathrm{min}$ $\left(2.8 \mathrm{~cm}^{3} / \mathrm{s}\right)$. During this phase, no proppant production was measured, and the normal stress was maintained constant. This suggests that material changes in the structure of the pack are of second-order importance.

Phase 3: Conductivity Increase without Proppant Production. From 165 minutes until approximately 195 minutes, the fracture conductivity increased steadily as the injection rate was increased from $170 \mathrm{ml} / \mathrm{min}\left(2.8 \mathrm{~cm}^{3} / \mathrm{s}\right)$ to $280 \mathrm{ml} / \mathrm{min}\left(4.7 \mathrm{~cm}^{3} / \mathrm{s}\right)$. At the same time, the measured injection pressure is less than what would be predicted by the Darcy fit to the phase 2 data. Throughout this phase, the normal stress was maintained constant, and no downstream proppant production was recorded. An increase in conductivity suggests that the increased flow rate may have forced out the remaining air in the pack or that there had been some mechanical re-arrangement of the pack at this time, perhaps resulting in the creation of more-conductive flow channels. Although no produced proppant was detected in the wellbore until the end of this phase, it is quite possible that some rearrangement of the pack had already occurred. The maximum value of the conductivity attained is about $1400 \mathrm{md}-\mathrm{ft}$, which is below some published estimates $\left(2200 \mathrm{md}-\mathrm{ft}\right.$ at a closure stress of $\left.41.38 \mathrm{MPa}^{1}\right)$ for conductivity of proppant packs with proppant diameters at the higher end of the sieved range.

\footnotetext{
${ }^{1}$ http://www.sintexminerals.com/images/SinterBallUpdate08_3.pdf
} 
Phase 4: Fracture Conductivity Reduces with Proppant Production. From 195 minutes until the normal stress was intentionally increased at 230 minutes, the fracture conductivity fell sharply from a peak value of about $1400 \mathrm{md}-\mathrm{ft}$. This conductivity reduction occurred as the injection rate was increased from $280 \mathrm{ml} / \mathrm{min}\left(4.7 \mathrm{~cm}^{3} / \mathrm{s}\right)$ to $520 \mathrm{ml} / \mathrm{min}\left(8.7 \mathrm{~cm}^{3} / \mathrm{s}\right)$. Proppant production increased over this period, although the pack had not yet failed catastrophically. This decline in fracture conductivity may reflect the gradual onset of non-Darcy (Forchheimer) flow, or, more accurately, the increasing importance of inertial pressure losses in the proppant pack as the injection rate was increased [see, for example, Scheidegger (1974), Barree and Conway (2004, 2007)]. In phase 4, the inertial pressure losses became dominant. Furthermore, because pressure progressively increased with the flow rate held constant, fines accumulation proximal to the wellbore is anticipated to be relevant.

Darcy's law closely fits the data at low flow rates, certainly throughout phase 2 . The slope of the straight line (labeled Darcy fit in Fig. 8) provides a good estimate of the coefficient $a$ defined in Eq. (4). The Darcy fit underestimates the injection pressure at higher injection rates in phase 4, suggesting that higher injection pressure is needed at higher injection rates because of the additional resistance to flow due to inertial effects. Not surprisingly, a quadratic fit to the data in Fig. 8 may be more appropriate:

$$
p_{i n j}=p_{e}-p_{w f}=\alpha Q+\beta Q^{2}
$$

where $Q$ is the volumetric flow rate $\left(\mathrm{m}^{3} / \mathrm{s}\right), p_{e}$ is the external pressure $(\mathrm{Pa}), p_{w f}$ is the wellbore pressure-atmospheric $(\mathrm{Pa})$, and $\alpha$, and $\beta$ are Forchheimer parameters that can be determined empirically. [SLD: I did not see injection pressure defined elsewhere in the text or in the nomenclature.]

Phase 5: Normal Stress Increased but Proppant Production Accelerates. From 230 minutes until the end of the test at approximately 250 minutes, the normal (closure) stress was increased from 13.8 MPa to approximately 23.6 MPa in an attempt to stabilize proppant production. In reality, the progressive increase in the applied normal stress was accompanied by increased proppant production and catastrophic loss of stability of the proppant pack.

\subsection{Linear Flow}

Qualitatively, the same mechanistic phases for fracture conductivity can be seen for the linear flow configuration (Fig. 11).

Fig. 11. Relationship between fracture conductivity, time, and proppant production.

\section{Critical Reynolds Number}

The propped fracture Reynolds number, $\mathrm{Re}_{\mathrm{p}}$, [SLD: In the equation, this should be written in roman rather than italic type (symbols derived from names are generally in roman type.] was calculated as

$$
R e_{p}=\frac{\rho V_{s} d_{p}}{\mu}
$$


Where $\rho$ is the fluid density $\left(998 \mathrm{~kg} / \mathrm{m}^{3}\right), V_{s}$ is the superficial fluid velocity $(\mathrm{m} / \mathrm{s}), \mu$ is the dynamic viscosity $(0.001 \mathrm{~Pa} \cdot \mathrm{s})$, and $d_{p}$ is the mean diameter of the $30 / 60$ proppant $(0.5 \mathrm{~mm})$ that was used in the experiments.

Figs. 12 and 13 show propped-fracture particle Reynolds numbers for each flow scenario; radial and linear, respectively. The particle Reynolds' number associated with proppant movement is approximate since width is not precisely known and since proppant production measurements in the linear flow test were not reliable during the first part of the test. Nevertheless, the values are in line with turbulent conditions (Ergun, 1952) and are substantially higher in the radial flow situation because the particles are more kinematically constrained.

Fig. 12. Reynolds number versus time is plotted for the situation where flow is radially converging into the wellbore. The Reynolds number critical value appears to be approximately about 6 . This value is substantially larger than for linear flow because of kinematic interactions between the proppant particles.

Fig. 13. Reynolds number versus time is plotted for the situation where flow is linear into the wellbore. The Reynolds number critical value appears to be approximately 1.5 .

\section{Post-Mortem}

After the testing was terminated, stresses were removed, the block was dried, and epoxy was circulated through the wellbore and fracture to immobilize the proppant. After the epoxy had cured, the block was slabbed (saw cut) above and below the horizontal fracture surface and the fracture surface was imaged. CT scans of the fracture are shown in Figs. 14 and 15. Areas of low proppant density appear black; areas of high density appear white. The white zones around the wellbore are beam hardening artifacts of the imaging process.

Fig. 14. Three-dimensional reconstruction of the fracture and its immediate surroundings. Areas of low proppant density appear black; areas of high density appear white. Clockwise from upper left: (a) plan view, (b) plan view showing where cross sections were taken, (c) through (f) cross-sectional views.

For the radially convergent flow situation, shown in Fig. 14, the images suggest the presence of lower-density, higher-permeability, channels that represent preferred fluid flow pathways. The proppant in these channels was ultimately transported to the wellbore.

Fig. 15. Post-test CT scan of proppant pack for the linear flow simulation, with and without annotation.

For the linear flow pack (Fig. 15), a more substantial eroded regime is evident immediately at the wellbore, and, to a lesser extent, in the upper left hand quadrant of the propped fracture in the images.

\section{Conclusions}

Although there is an apparent reluctance to use proppant in geothermal hydraulic stimulation operations, the legacy of hydraulic fracturing operations does not show any obvious evidence of operational problems associated with proppant flowback. This paper describes the experimental results of convergent and linear flow into a wellbore through an initially packed fracture. The experiment was conducted on granite blocks to evaluate the mechanics of proppant flowback in geothermal wells. The key observations are as follows. 
1. Darcy flow was evident at low flow rates, as anticipated, and under the loading conditions adopted, the proppant was relatively immobile.

2. Before physical proppant back-production was recorded, calculated conductivity increased. This was not anticipated. It may be that nascent channels were evolving in areas where preferential flow was occurring, even before proppant was detected downstream of the fracture.

3. Channels were definitely evident in the radially converging flow test. This is an extremely important observation and merits further evaluation. A grossly stabilized pack developed but wormholes evolved. The extent and ultimate stability of these wormholes is relevant.

4. Critical particle Reynolds numbers of 1.5 and 6 were inferred for the linear and radial flow regimes, respectively. [SLD: The two numbers were discrete (did not seem to be part of a range).] The proppant is apparently more stable in the radial flow domain. If cased and cemented completions are considered for geothermal applications, in conjunction with propped fracturing, perforations will likely inhibit proppant flowback more than slotted completions.

5. With increasing rates above a critical value (as indicated by the particle Reynolds' number, for example), conductivities in the radial flow regime rapidly declined. Two mechanisms could be at play. The first is the progressive importance of inertial effects. The second mechanism is near-wellbore permeability reduction associated with fines migration. This is likely as the pressure continued increasing even when the rate was maintained constant for a substantial period of time. The conductivity reduction was not observed in the linear flow tests because the Reynolds numbers were lower.

6. It was difficult to determine if fracture roughness inhibited proppant flowback. Only two tests were conducted, and the surface roughnesses were similar. Additional, simpler tests could be useful in determining the role of roughness alone. Additional large block tests could be used to assess flowback into other near-wellbore geometries (abrasively jetted slots, perforations, etc.).

[SLD: From examples in the sample issue online, it looks like the nomenclature will be in a separate box in a column within the text (so it would not be a numbered section. Units are separated from definitions by a comma (rather than being in parentheses, as shown by marked changes in the first few entries, below). The list should be ordered by letter symbols, Greek symbols, and then subscripts and superscripts. One example is in the paper by Lehua Pan et al. in the sample issue: http://www.sciencedirect.com/science/journal/03756505/53.]

\section{Table of Nomenclature}

$B$

$d_{p}$

$F_{p}$

$F_{s}$

$k$........

$k_{f}$

$k_{f} w$

$p$.

$p_{e}$

$p_{w f}$

$Q$

$r$. formation volume factor mean $30 / 60$ proppant diameter, $\mathrm{mm}$ pressure drag, $\mathrm{N}$ drag attributed to viscous effects, $\mathrm{N}$ effective permeability $\left(\mathrm{m}^{2}\right)$ effective fracture permeability $\left(\mathrm{m}^{2}\right)$ fracture conductivity (md-ft) pressure $(\mathrm{Pa})$ external pressure $(\mathrm{Pa})$ wellbore pressure - atmospheric ( $\mathrm{Pa})$ volumetric flow rate $\left(\mathrm{m}^{3} / \mathrm{s}\right)$ .particle radius $(\mathrm{m})$ 


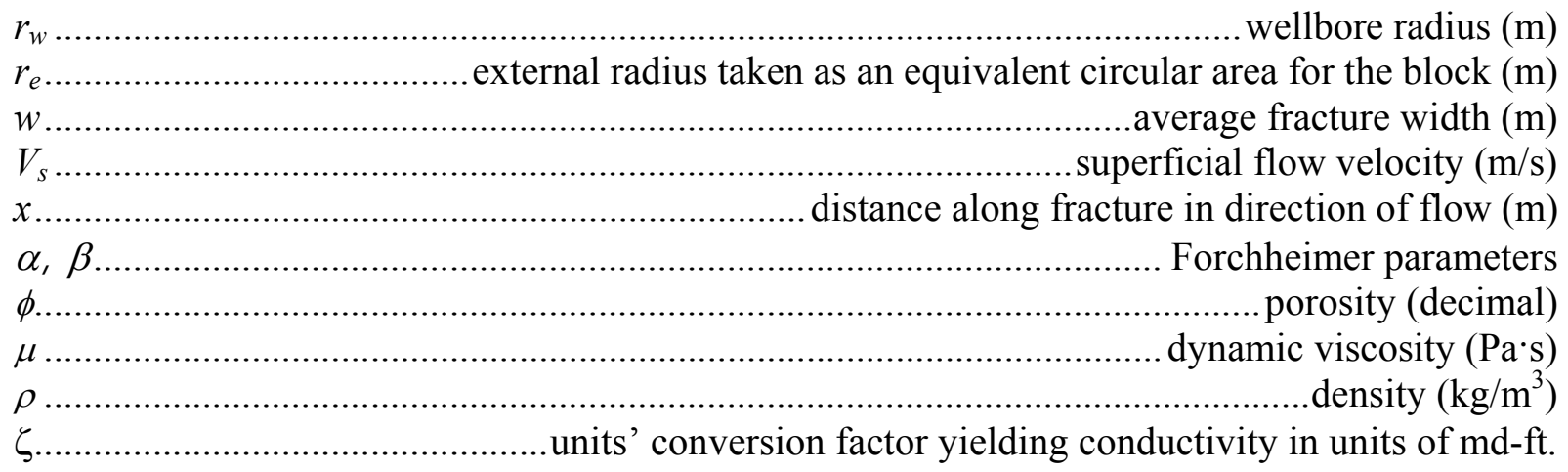

\section{Acknowledgments}

This work was funded by the United States Department of Energy's Geothermal Technologies program under contract DE-FG36-08GO18189, "The Role of Geochemistry and Stress on Fracture Development and Proppant Behavior in EGS Reservoirs". The staff at TerraTek, A Schlumberger Company, is recognized for their assistance in conducting the experiments. The management at TerraTek, A Schlumberger Company, is acknowledged for allocating staff time and equipment to the project. Assistance of Erika Anderson in editing and figure preparation is gratefully acknowledged.

[SLD: Changes to SPE references (including DOI) can be checked in onepetro.org. Note that onepetro.org has the spelling Milton-Tayler and has Parker rather than Porter as the first author of Understanding Proppant Flowback.]

\section{References}

Andrews, J.S., Kjørholt M.W., 1998. Rock Mechanical Principles Help to Predict Proppant Flowback from Hydraulic Fractures. Proceedings, SPE/ISRM Eurorock '98, Trondheim, Norway, 381-390, DOI: 10.2118/47382-MS.

Asgian, M.I., Cundall, P.A., Brady, B.H., 1995. The Mechanical Stability of Propped Hydraulic Fractures: A Numerical Study. Journal of Petroleum Technology, 47(3), 203-208. DOI: 10.2118/28510-PA.

Barree, R.D., Conway, M.W., 2004. Beyond Beta Factors: A Complete Model for Darcy, Forchheimer, and Trans-Forchheimer Flow in Porous Media. SPE Annual Technical Conference and Exhibition. Houston, Texas, USA, DOI: 10.2118/89325-MS.

Barree, R.D., Conway, M.W., 2007. Multiphase Non-Darcy Flow in Proppant Packs. SPE Annual Technical Conference and Exhibition, Anaheim, California, DOI: 10.2118/109561-MS.

Daneshy, A., 2005. Proppant Distribution and Flowback in Off-Balance Hydraulic Fractures. SPE Production \& Facilities, 20(1), 41-47.

Duenckel, R., Conway, M.W., Eldfred, B., Vincent, M.C., 2011. Proppant Diagenesis-Integrated Analyses Provide New Insights into Origin, Occurrence and Implications for Proppant Performance, SPE Hydraulic Fracturing Technology Conference and Exhibition. The Woodlands, Texas, USA, DOI: $10.2118 / 139875-\mathrm{MS}$.

Ergun, S., 1952. Fluid Flow Through Packed Columns. Chem. Eng. Prog. 48, 89-94.

Fredd, C.N., McConnell, S.B., Boney, C.L., England, K.W., 2001. Experimental Study of Fracture Conductivity for Water-Fracturing and Conventional Fracturing Applications. SPE Journal, 6(3), 288-298. DOI: 10.2118/74138-PA.

Gidley, J.L., Holditch, S.A., Veatch, R.W., Jr., eds.,1989. ed. Recent Advances in Hydraulic Fracturing. SPE Monograph Series, 12. Dallas, TX: Society of Petroleum Engineers. [SLD: Is this is http://store.spe.org/Recent-Advances-In-Hydraulic-Fracturing--P66.aspx, then the editors are Gidley, J.L., Holditch, S.A., Nierode, D.E., and Veatch, R.W., Jr. and the date is 1990.] 
Goel, N., Shah, S., 1999. Experimental Investigation of Proppant Flowback Phenomena Using a Large Scale Fracturing Simulator. SPE Annual Technical Conference and Exhibition, Houston, Texas, USA, USA, DOI: 10.2118/56880-MS.

King, M.J., 1988. Viscous Fingering and Probabilistic Simulation. In Numerical Simulation in Oil Recovery, M.F. Wheeler (ed.), 161-176. New York: Springer Verlag.

Mauer Engineering, 1980. Geothermal Fracture Stimulation Technology, Volume I, Fracturing Proppants and Their Properties.

Milton-Tayler, D, Stephenson, C., Asgian, M.I., 1992. Factors Affecting the Stability of Proppant in Propped Fractures: Results of a Laboratory Study. SPE Annual Technical Conference and Exhibition, Washington, D.C., USA, DOI: 10.2118/24821-MS.

Parker, M., Weaver, J., Van Batenburg, D., 1999. Understanding Proppant Flowback. SPE Annual Technical Conference and Exhibition, Houston, Texas, USA, DOI: 10.2118/56726-MS.

Raymond, L.R., Binder, G.G., Jr. 1967. Productivity of Wells in Vertically Fractured, Damaged Formations. Journal of Petroleum Technology, 19(1), 120-130, DOI: 10.2118/1454-PA.

Robinson, B.M., Holditch, S.A., Whitehead, W.S., 1988. Minimizing Damage to a Propped Fracture by Controlled Flowback Procedures. Journal of Petroleum Technology, 40(06), 753-759, DOI: 10.2118/15250-PA.

Romero, D.J., Valkó, P.P. Economides, M.J., 2003. Optimization of the Productivity Index and the Fracture Geometry of a Stimulated Well with Fracture Face and Choke Skins, SPE Production \& Facilities, 18(1), 57-64, DOI: 10.211881908-PA.

Santarelli, F.J., Sanfilippo, F., Embry, J.M., White, M., Turnbull, J., 2011. The Sanding Mechanisms of Water Injectors and their Quantification in Terms of Sand Production: Example of the Buzzard Field (UKCS). SPE Annual Technical Conference and Exhibition. Denver, Colorado, USA, DOI: 10.2118/146551-MS.

Scheidegger, A.E., 1974. The Physics of Flow Through Porous Media. Third Edition. University of Toronto Press.

Sinclair, A.R., Graham, J.W., Sinclair, C.P. 1983. Well Stimulation with Resin-Coated Proppants. SPE Production Operations Symposium. Oklahoma City, Oklahoma, USA, DOI: 10.2118/11579-MS.

Stoddard, T., McLennan, J., Moore, J., 2011. Fracture Conductivity of a Bauxite-Propped Geothermal System at In-Situ Conditions. 36th Stanford Workshop on Geothermal Reservoir Engineering. Stanford, CA.

van Dam, D.B., de Pater, C.J., 1999. Roughness of Hydraulic Fractures: The Importance of In-Situ Stress and Tip Processes. SPE Annual Technical Conference and Exhibition. Houston, Texas, USA, DOI: 10.2118/56596-MS. 

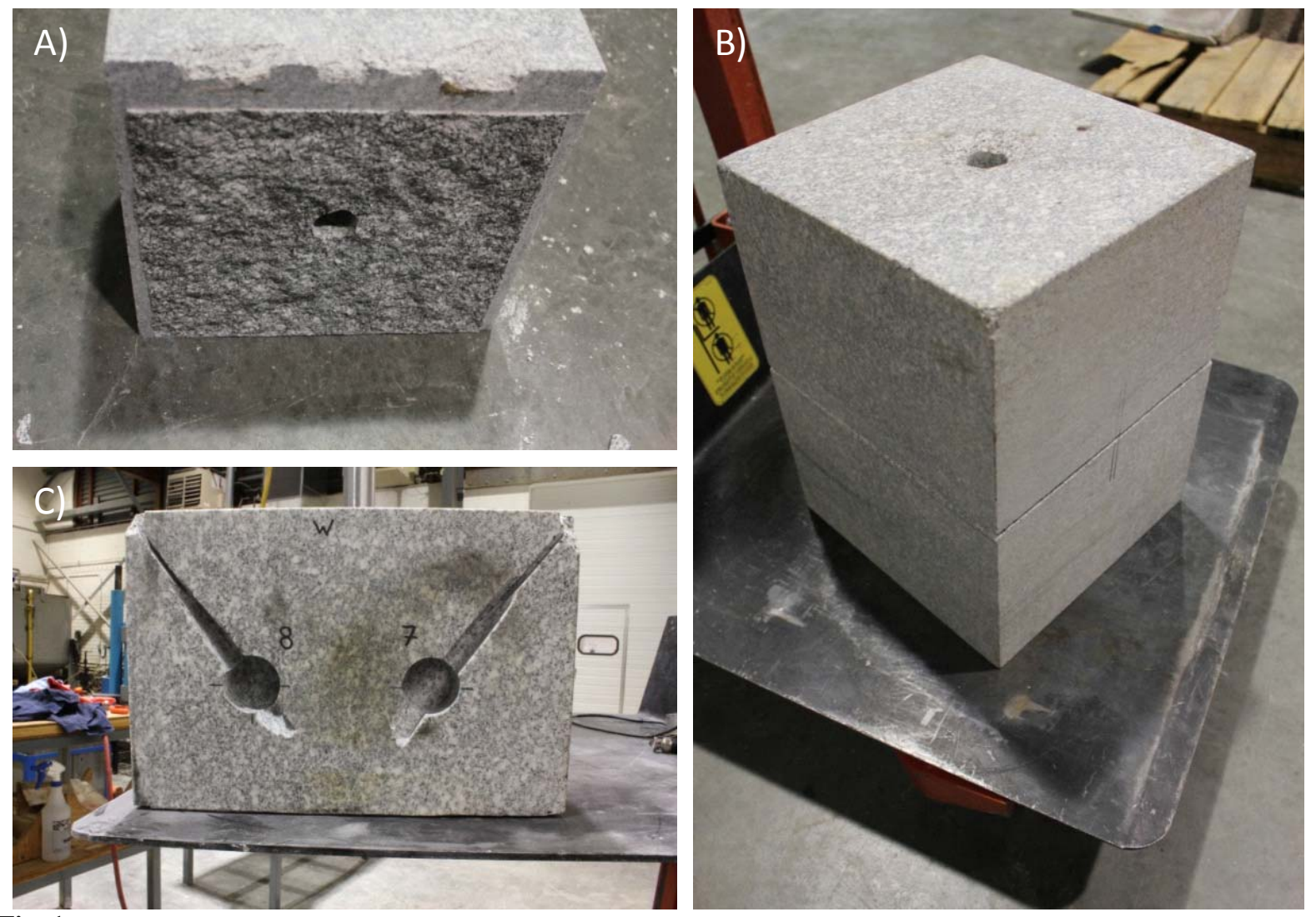

Fig. 1.

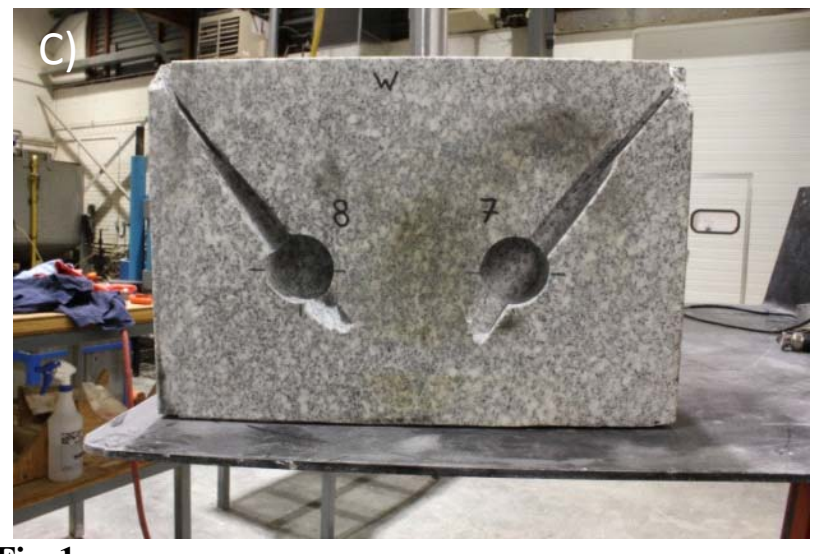



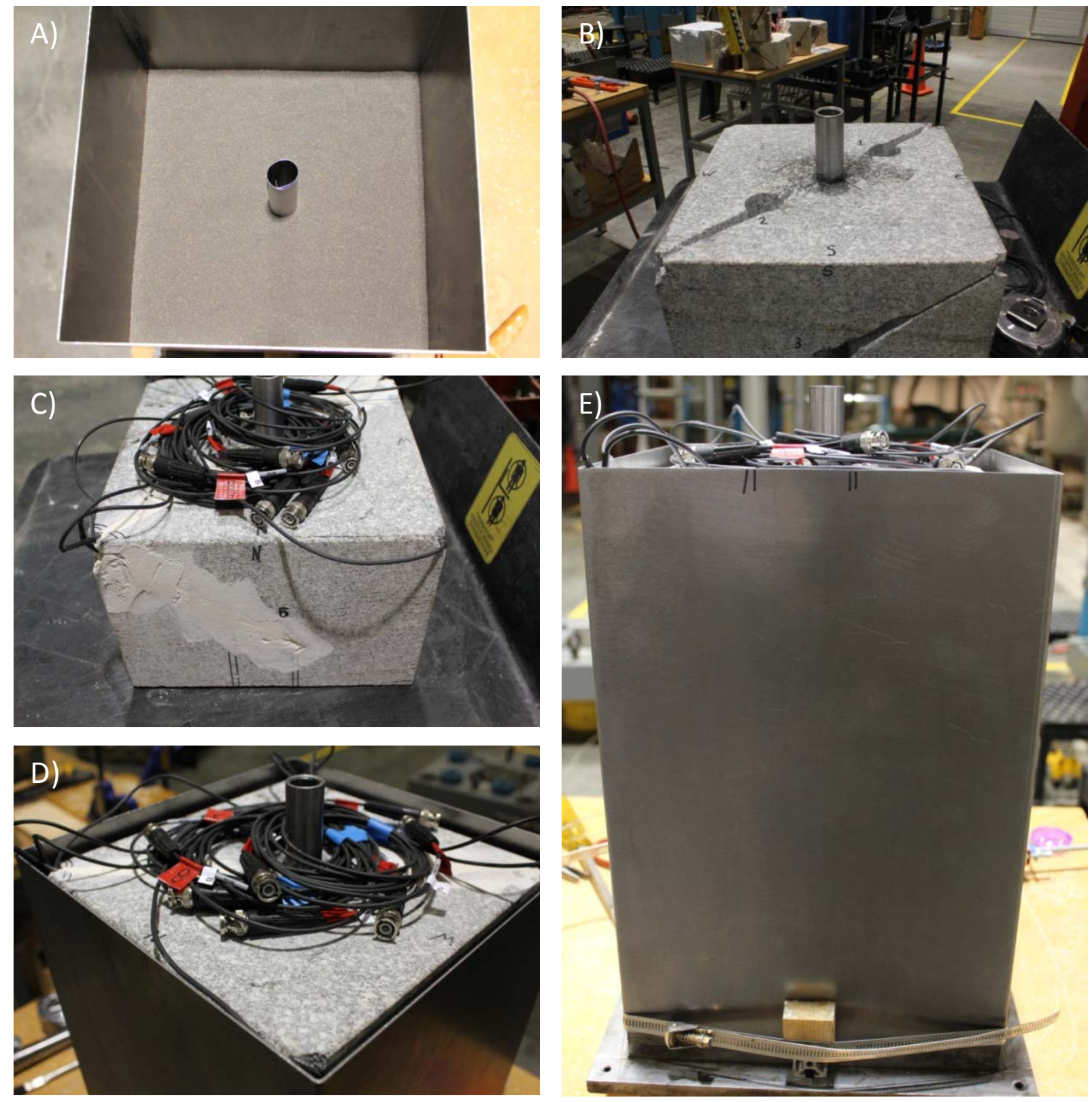

Fig. 2. 


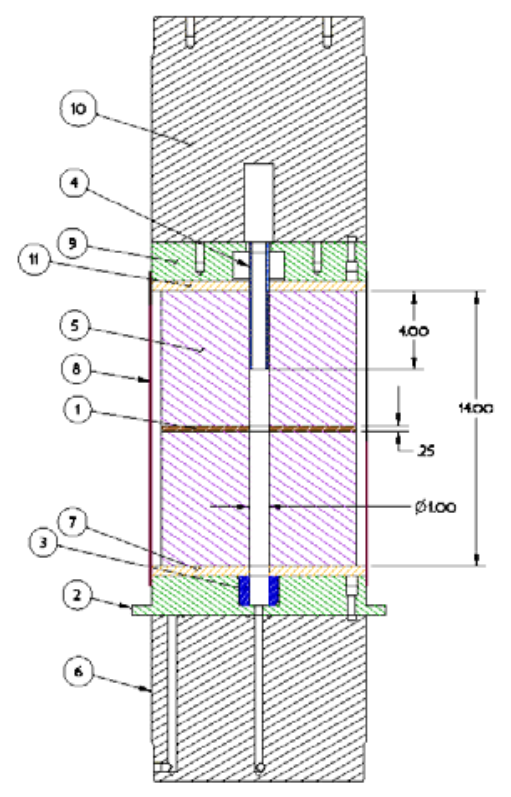

A)

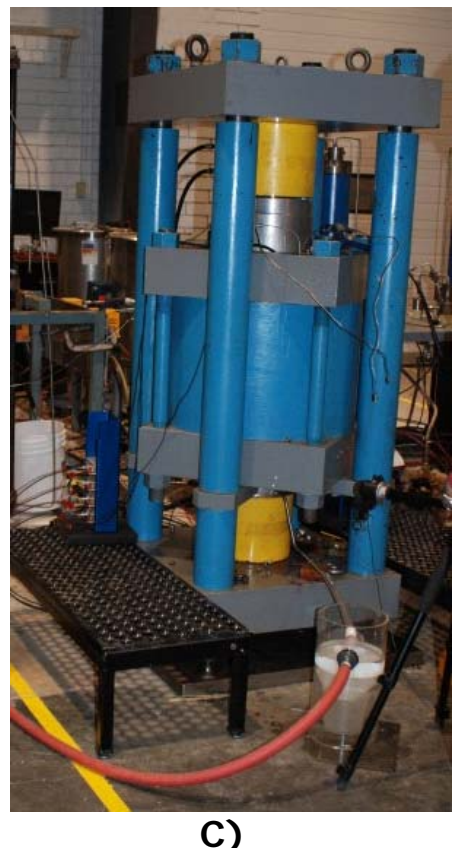

C)

Fig. 3.

B) 


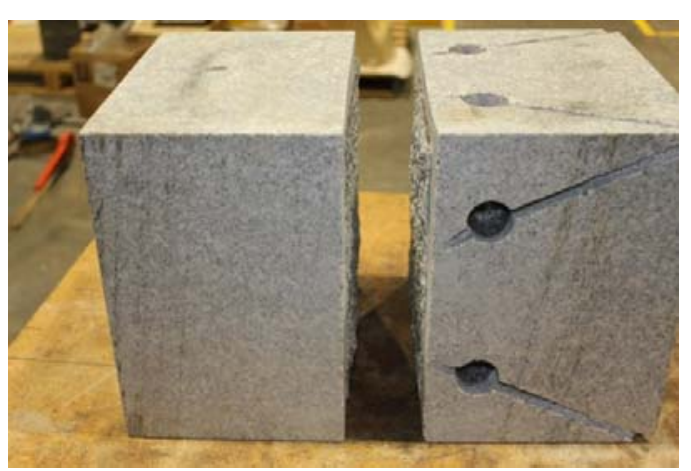

A)

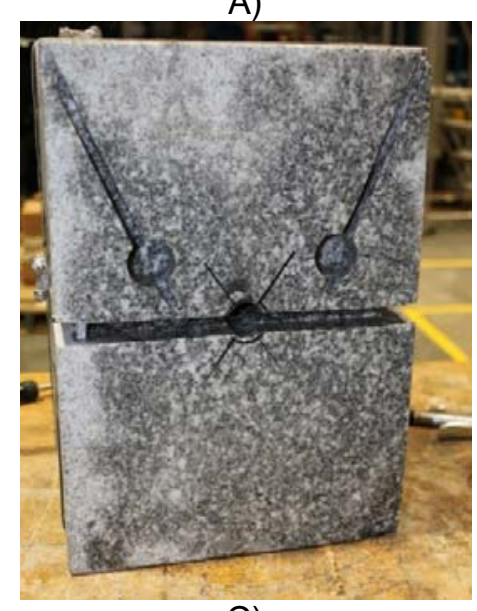

C)

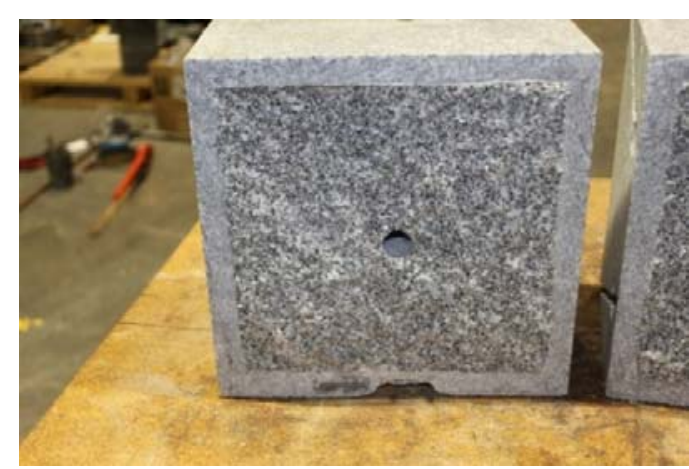

B)

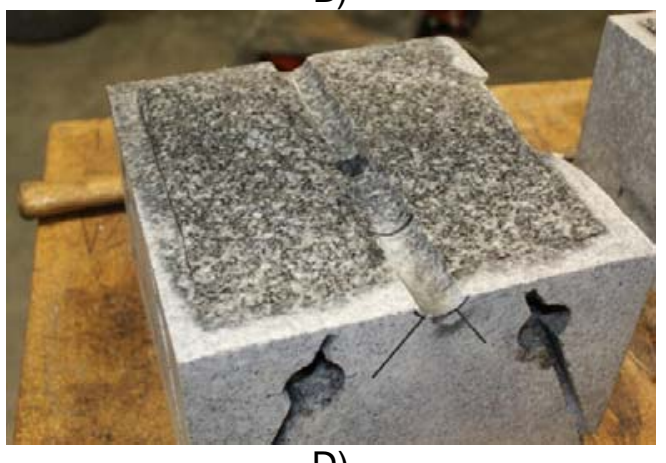

D)

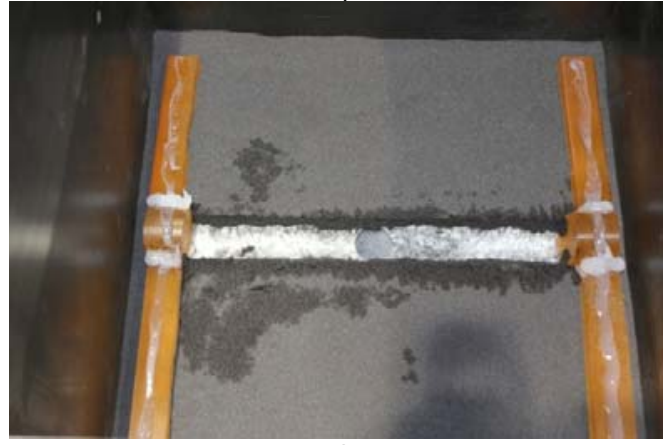

E)

Fig. 4. 


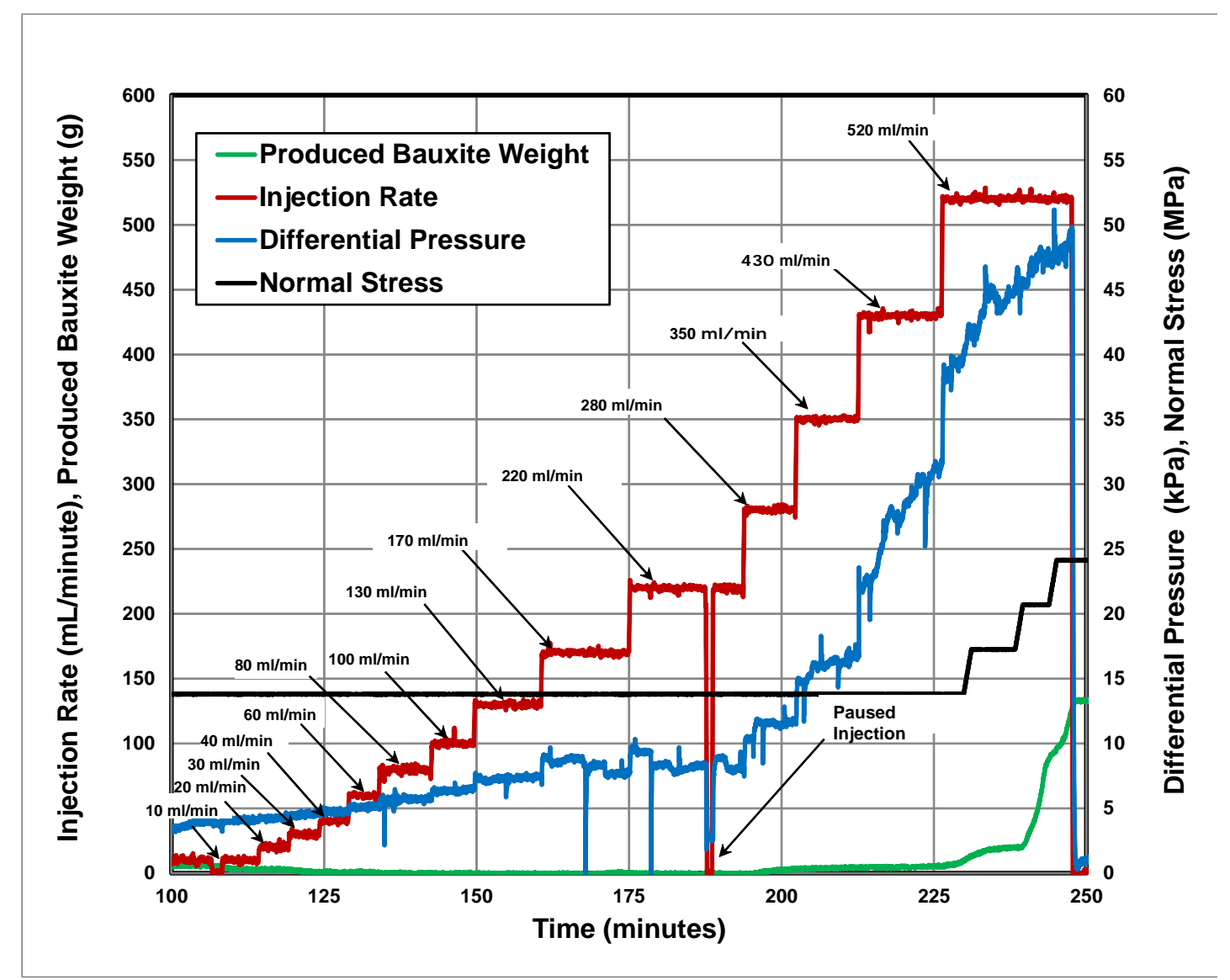

Fig. 5. 


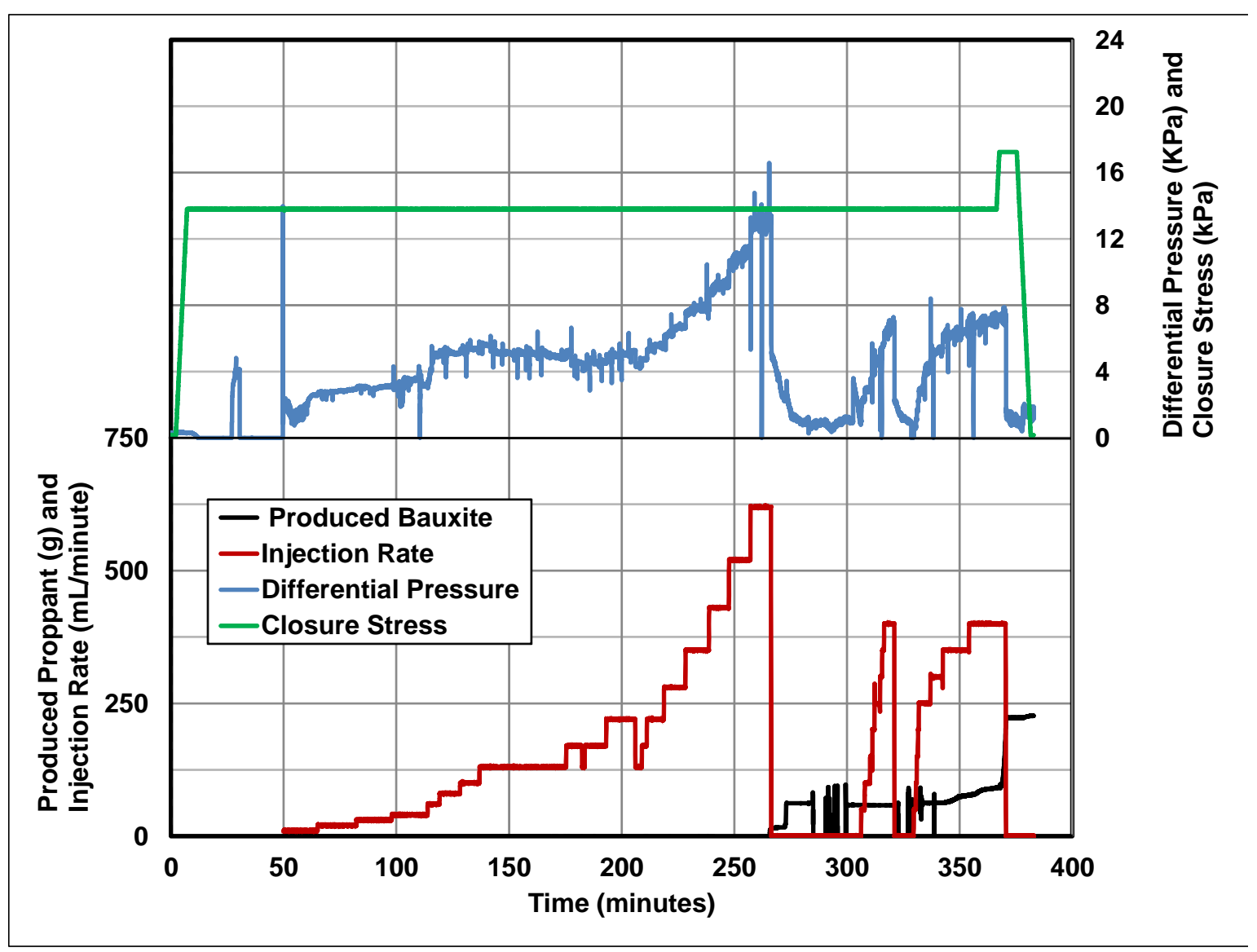

Fig. 6. 


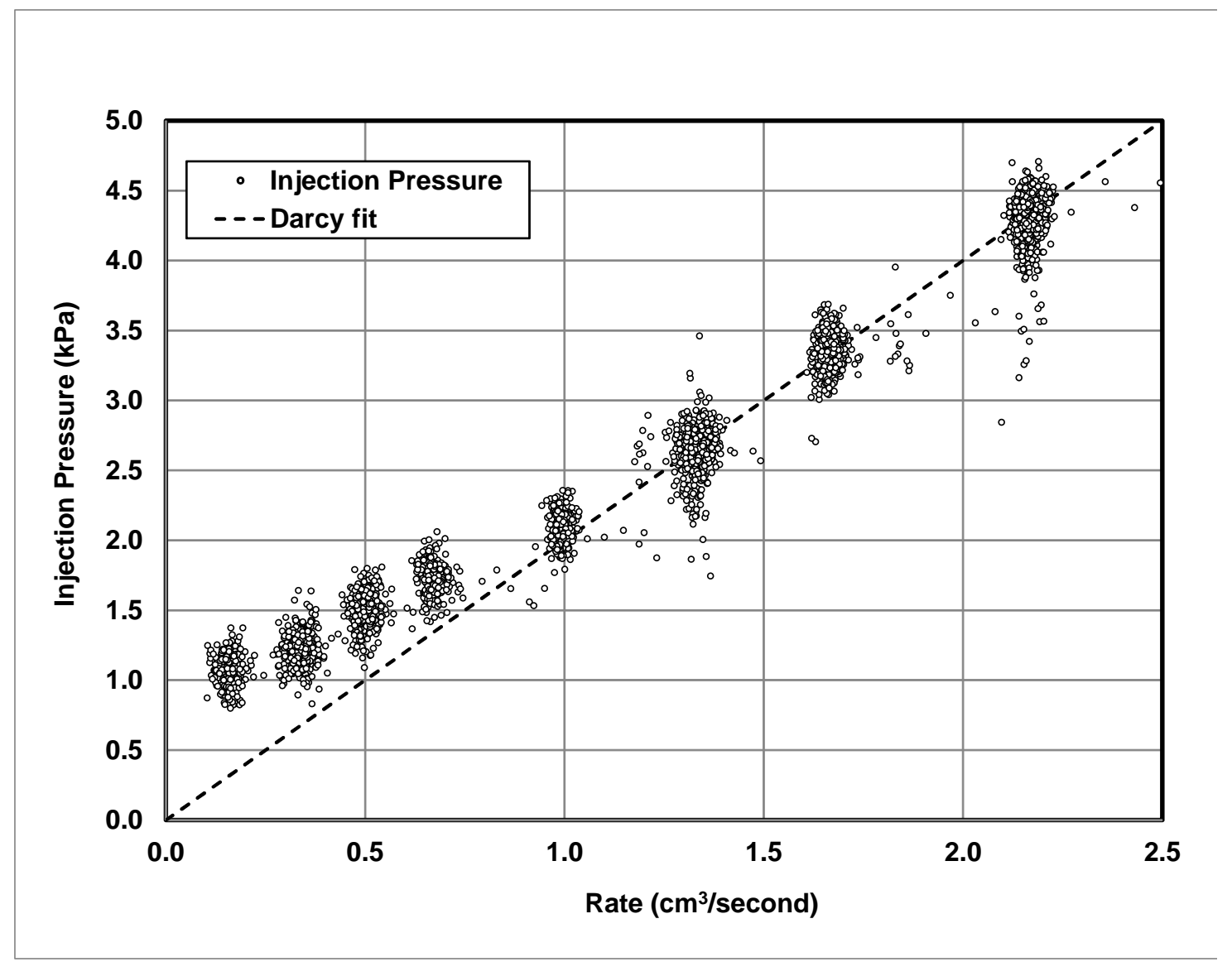

Fig. 7. 


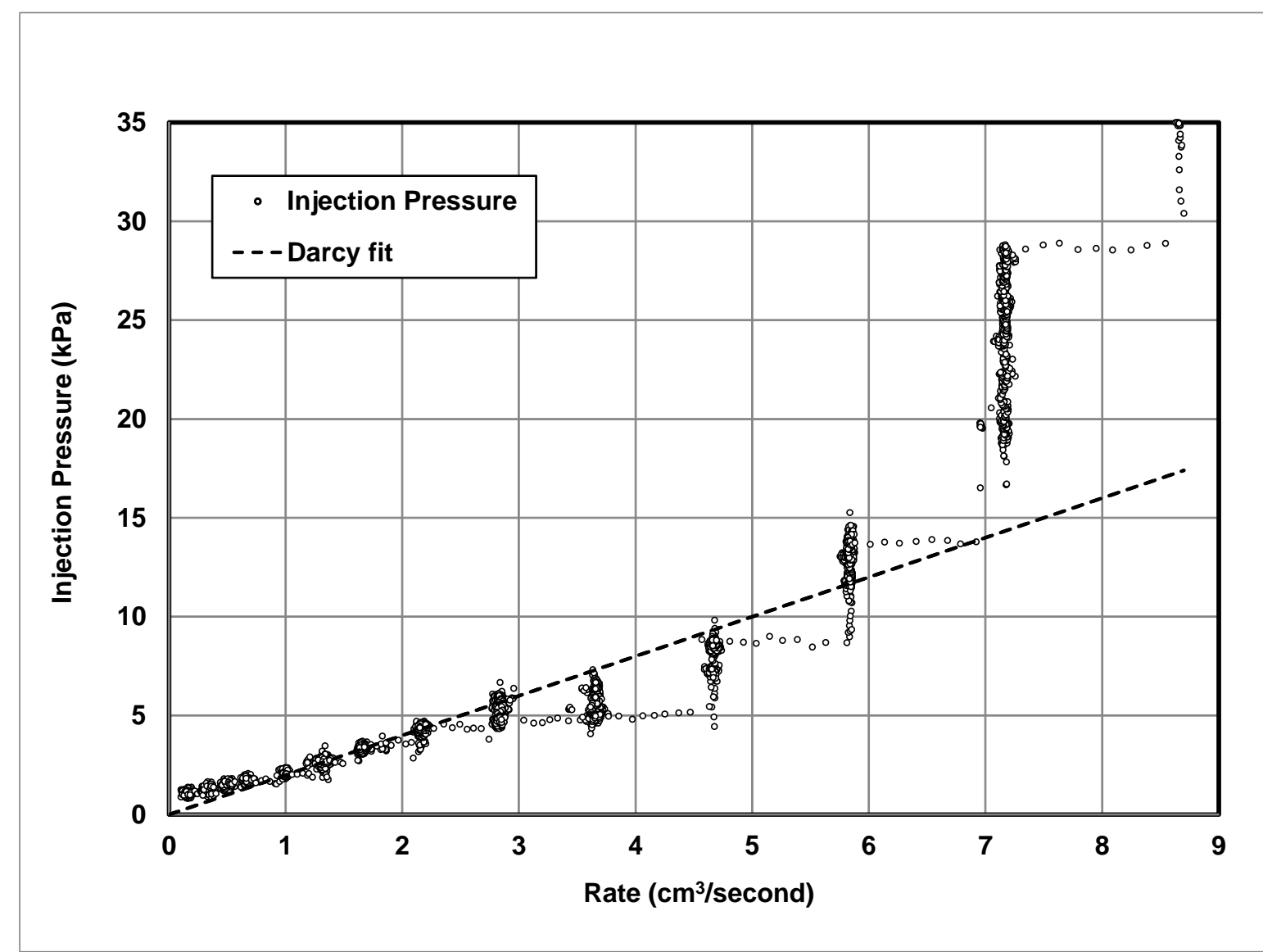

Fig. 8. 


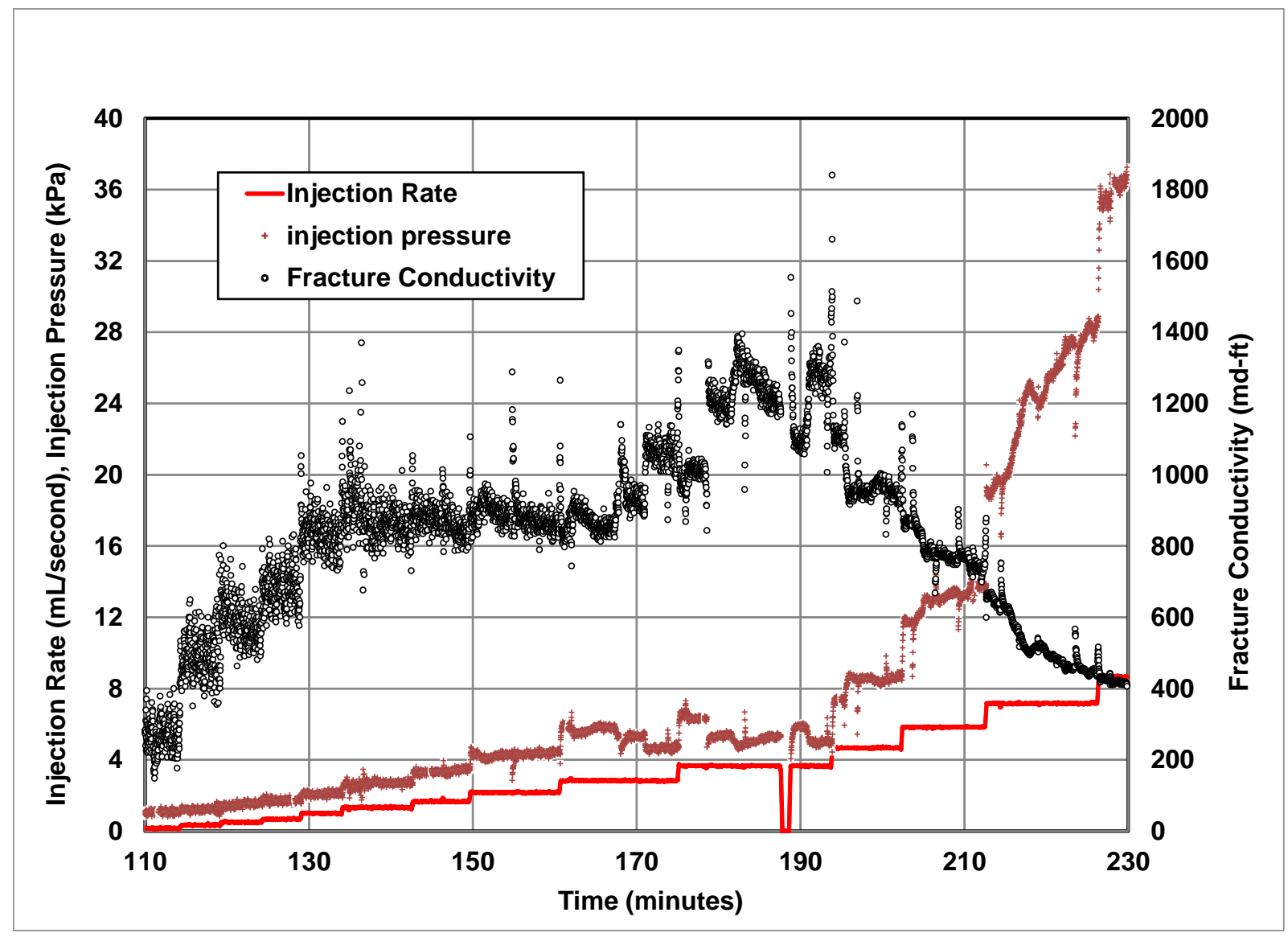

Fig. 9. 


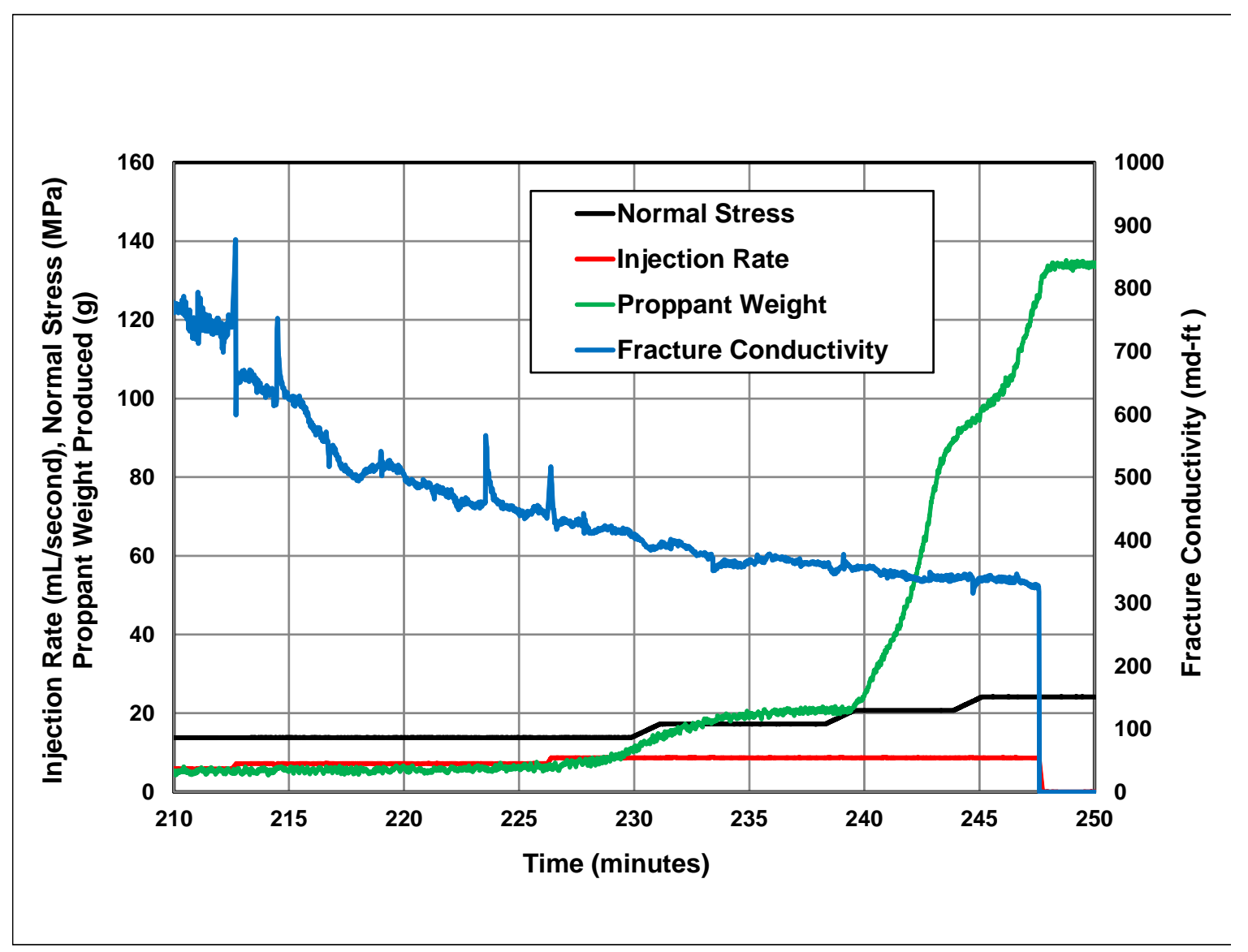

Fig. 10. 

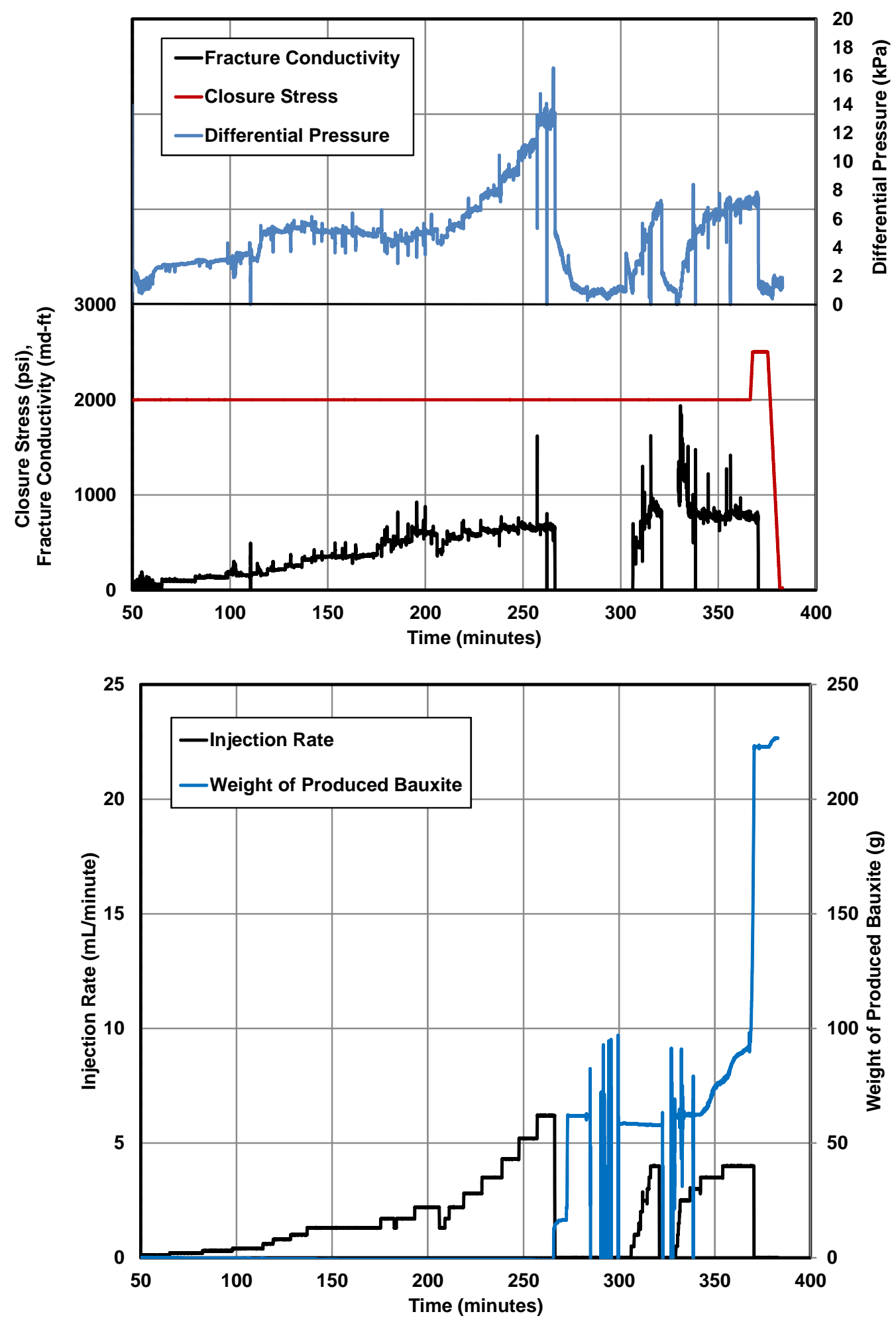

Fig. 11. 


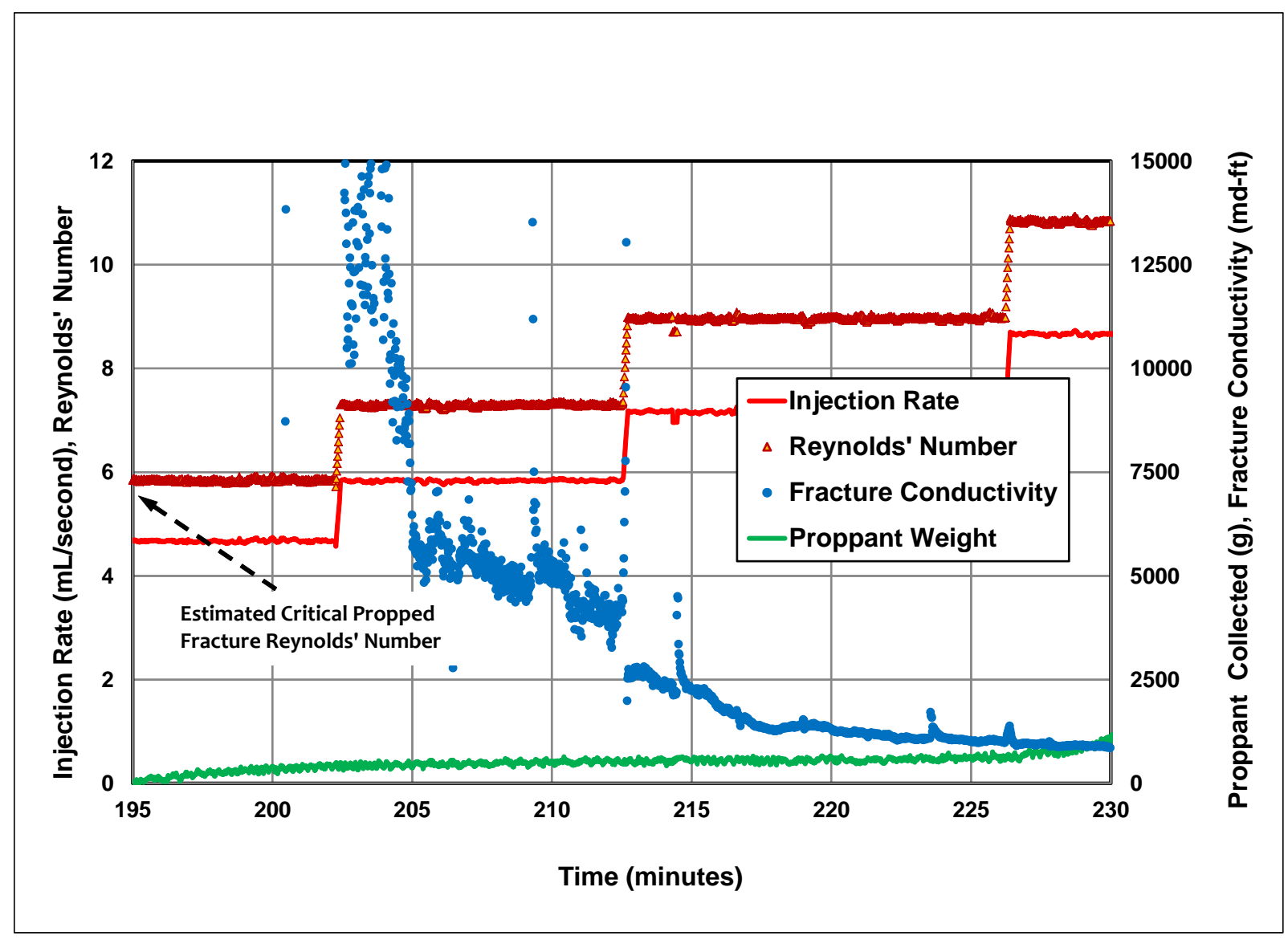

Fig. 12. 


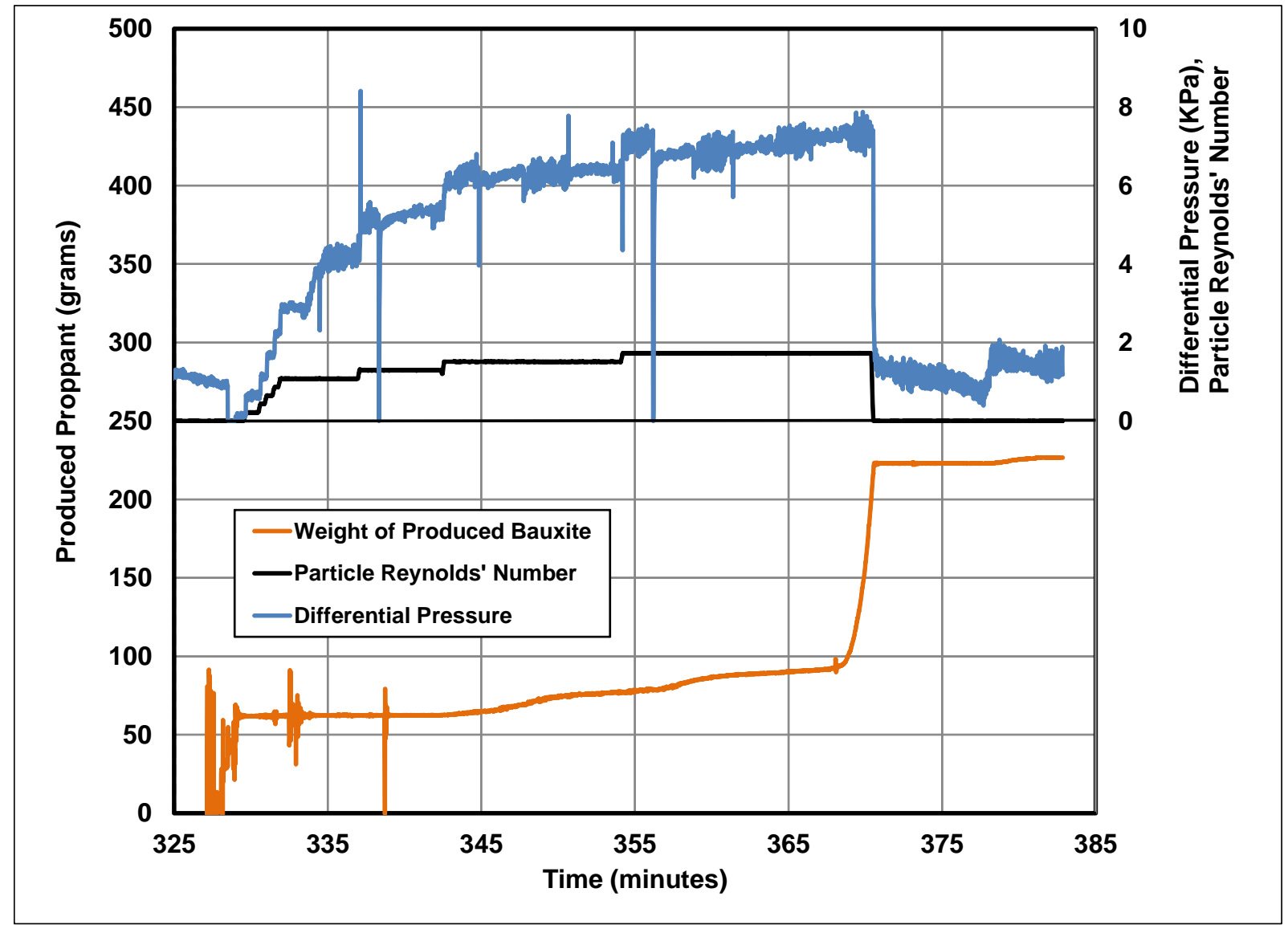

Fig. 13. [SLD: Reynolds' Number should be Reynolds Number.] 

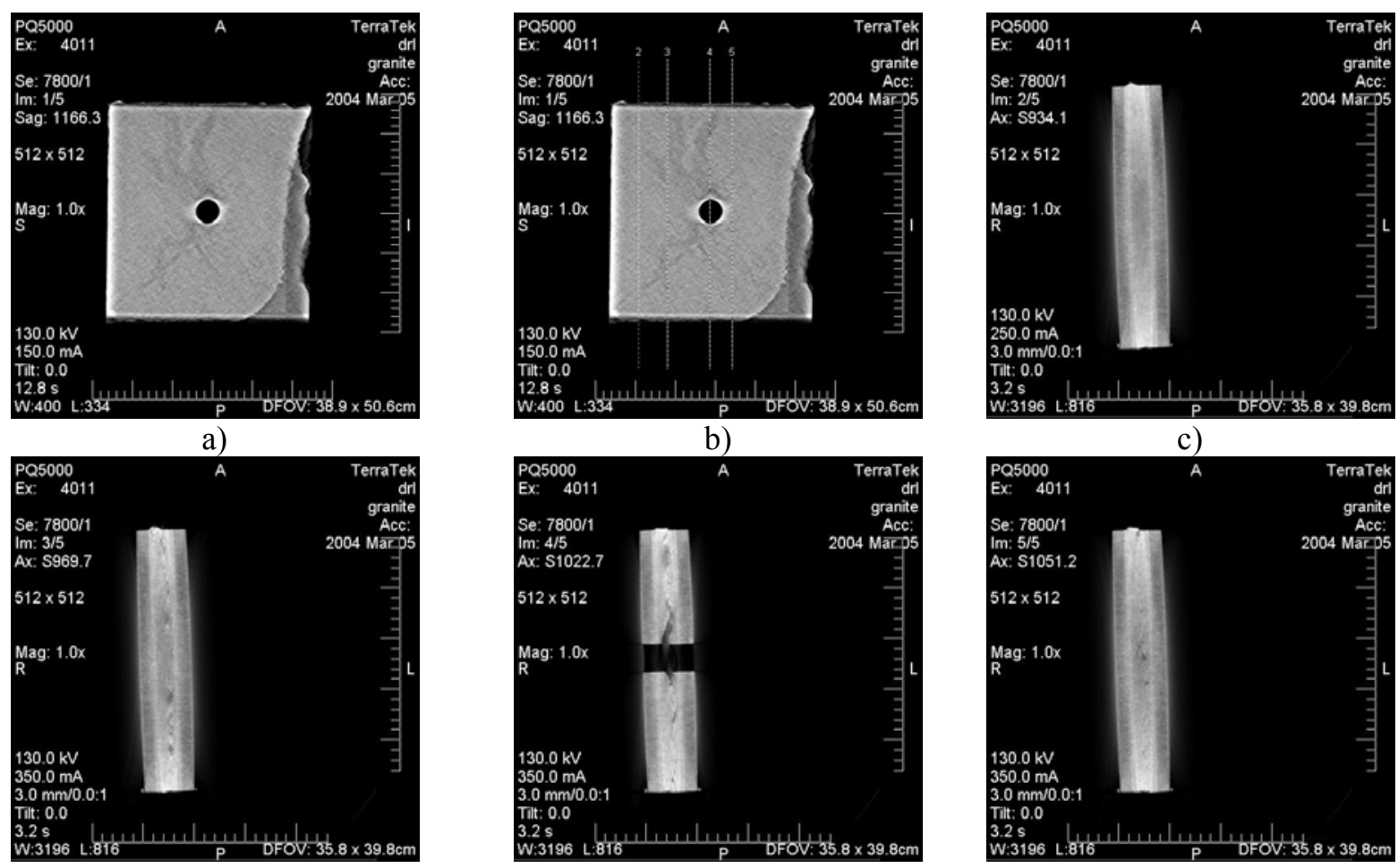

b)

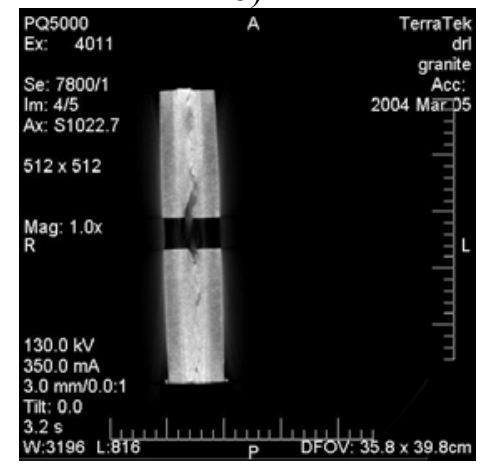

c)

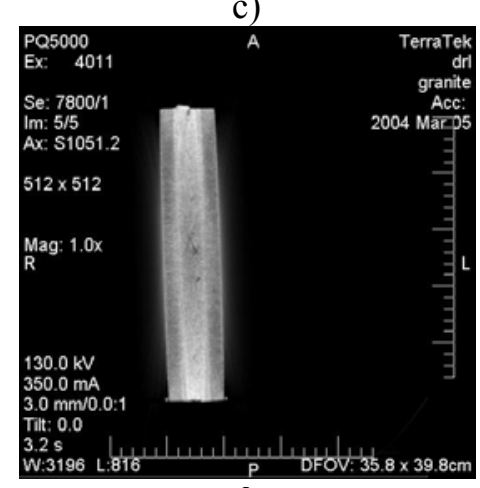

e)

f)

Fig. 14. 

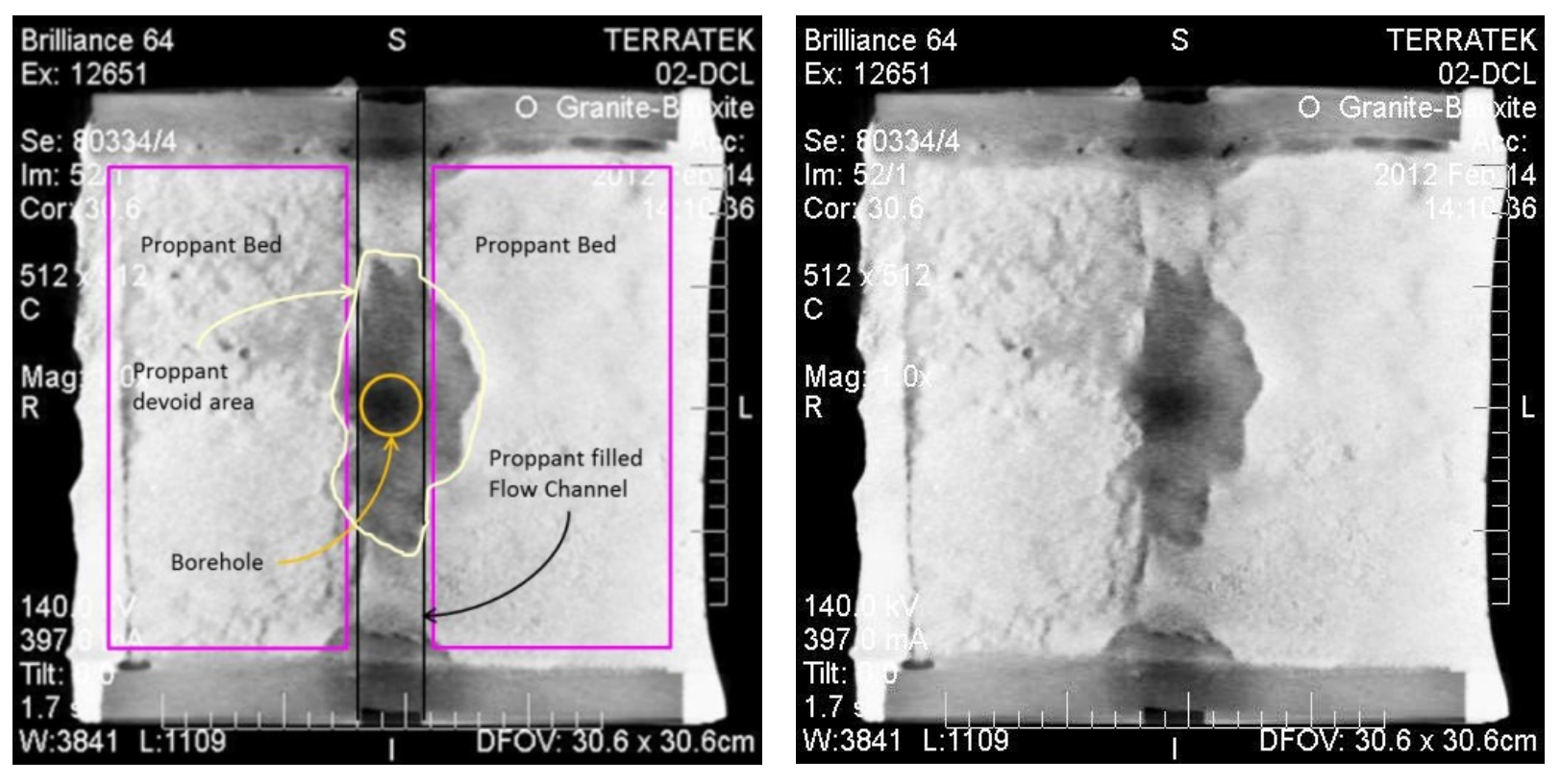

Fig. 15. 
[SLD: Note that the in-text versions of the figure captions were edited.]

Fig. 1. A) View of the granite block with nominal external dimensions of $0.203 \mathrm{~m} \times 0.203 \mathrm{~m} \times 0.357 \mathrm{~m}$. The edges were scored and a fracture was mechanically created by splitting with a wedge. B) The two block halves stacked with no proppant. The $25.4 \mathrm{~mm}$ diameter central hole is visible in this view and in Fig. 1A. C) Biscuits were cut on the ends of the block for the installation of microseismic transducers.

Fig. 2. Fabrication of the radially convergent flow sample. A) View looking down on the proppant-covered lower block half. A coiled sheet forming a tube extending vertically out of the lower block half is designed to keep proppant in place during fabrication and is extracted after the top block is lowered in place. B) Top half of the fractured block, showing microseismic biscuits and cable conduits cut into the rock. C) Microseismic/acoustic transducers have been installed D) Microseismic/acoustic transducer cabling is seen and the block has been dropped into the flexible external container. (E) View of external canister containing the sample.

Fig. 3. A) Radial Convergent Flow: Elevation view of block, with the wellbore venting downwards to a gravimetric measurement system (not shown). The dimensions on the plans are in inches. The approximate proppant pack thickness is indicated as $6 \mathrm{~mm}$ ( 0.25 inches). The entire unit was lowered into a reaction frame allowing independent application of stresses in three orthogonal directions. This configuration allows radial convergent flow into the wellbore. Key: 1 - bauxite bead layer, 2 - bottom loading plate, 3 - spacer, 4 - casing stub, 5 - granite sample, 6 lower ram, 7 - lower urethane seal, 8 - sealing canister, 9 - upper loading plate, 10 - upper ram, 11 - upper urethane seal. B) Linear flow configuration. Key: 1 - bauxite bead layer, 2 - bottom loading plate, 3 - spacer, 4 - granite sample, 5 - spacer, 6 - lower ram, 7 - lower urethane seal, 8 - sealing canister, 9 - upper loading plate, 10 - upper ram, 11 - upper urethane seal, 12 - urethane borehole plug, 13 - urethane seal, 14 - upper urethane seal. C) Polyaxial frame with sample installed.

Fig. 4. A) View of the split granite block (for the linear flow test) with nominal external dimensions of $0.203 \mathrm{~m} \mathrm{x}$ $0.203 \mathrm{~m}$ x $0.357 \mathrm{~m}$. The edges were scored and a fracture was mechanically created by splitting with a wedge. B) A drainhole was drilled to allow produced proppant to exit the block and be gravimetrically collected. C) Biscuits were cut on the ends of the block for the installation of acoustic transducers. A wellbore was drilled along the fracture plane, intersecting the drainhole. D) View of wellbore, drainhole and granite fracture surface. E) View of wellbore, drainhole, bauxite on the lower half of the block and sealed ends. After mating with the upper block external flow will be directed through the proppant pack linearly towards the wellbore.

Fig. 5. Overall testing chronology for the radial convergent flow test. The differential pressure is the pressure drop through the hydraulic fracture. The normal stress is the closure stress analog - stress acting normal to the propped fracture. The produced bauxite weight reflects proppant production out of the fracture into the wellbore. Proppant was produced at slightly above background levels (i.e., periodic and small masses) until the injection rate change at approximately 226 minutes. Once the normal stress was increased to approximately $20.5 \mathrm{MPa}$ (at approximately 239 minutes), proppant production increased substantially. A further increase in normal stress (at $\sim 244$ minutes) corresponded with a further increase in proppant production rate. Proppant production was arrested only when the flow was terminated.

Fig. 6. Overall testing chronology for the linear flow test. The differential pressure is the pressure drop through the hydraulic fracture. The normal stress is the closure stress analog - stress acting normal to the propped fracture. The produced bauxite weight reflects proppant production out of the fracture into the wellbore.

Fig. 7. The injection pressure is the upstream pressure minus zero (atmospheric gage pressure existing at the exit from the fracture). The raw upstream pressure reading was corrected to try to reflect the pressure drop occurring only through the horizontal fracture. Upstream pressure was plotted against rate (before fluid breakthrough). A basic first order fit was used and this was extrapolated to correct differential pressures after fluid breakthrough.

Fig. 8. The injection pressure is the upstream pressure minus zero (atmospheric gage pressure existing at the exit from the fracture). This figure shows the fit using Darcy flow relationships (see also Fig. 7) and deviations from this fit at higher flow rates. The closure stress for all of these data was maintained constant at $13.79 \mathrm{MPa}$. 
Fig. 9. Relationship between fracture conductivity, injection pressure and injection rate. The stress normal to the propped fracture was maintained constant during this portion of the test.

Fig. 10. Relationship between decreasing fracture conductivity, time and proppant production. The conductivity and proppant produced are shown on a Cartesian scale. This plot shows time beyond that indicated in Fig. 9. The rate of proppant production accelerates just before 230 minutes. The injection rate change at approximately 226 minutes may have triggered this increase in proppant production. Increases in the closure stress appeared to destabilize the proppant further.

Fig. 11. Relationship between fracture conductivity, time and proppant production.

Fig. 12. Reynolds' number versus time is plotted for the situation where flow is radially converging into the wellbore. The critical value appears to be approximately about 6 . This value is substantially larger than for linear flow because of kinematic interactions between the proppant particles.

Fig. 13. Reynolds' number versus time is plotted for the situation where flow is linear into the wellbore. The critical value appears to be approximately 1.5 .

Fig. 14. Three-dimensional reconstruction of the fracture and its immediate surroundings. Areas of low proppant density appear black; areas of high density appear white. Clockwise from upper left: (a) plan view, (b) plan view showing where cross-sections were taken (c) through (f) cross-sectional views.

Fig. 15. Post-test CT scan of proppant pack for the linear flow simulation, with and without annotation. 